\title{
The Coxsackievirus-Adenovirus Receptor Reveals Complex Homophilic and Heterophilic Interactions on Neural Cells
}

\author{
Christopher Patzke, ${ }^{1}$ Klaas E. A. Max ${ }^{2}$ Joachim Behlke, ${ }^{2}$ Jadwiga Schreiber, ${ }^{1}$ Hannes Schmidt, ${ }^{1}$ Armin A. Dorner, ${ }^{1}$ \\ Stephan Kröger, ${ }^{4}$ Mechthild Henning, ${ }^{1}$ Albrecht Otto, ${ }^{3}$ Udo Heinemann, ${ }^{2,5}$ and Fritz G. Rathjen ${ }^{1}$ \\ ${ }^{1}$ Developmental Neurobiology Group, ${ }^{2}$ Macromolecular Structure and Interaction Group, and ${ }^{3}$ Proteomics and Molecular Mechanisms of \\ Neurodegenerative Disorders Group, Max-Delbrück-Centrum für Molekulare Medizin, 13092 Berlin, Germany, ${ }^{4}$ Ludwig-Maximilians-Universität, 80336 \\ München, Germany, and ${ }^{5}$ Freie Universität Berlin, 14195 Berlin, Germany
}

The coxsackievirus-adenovirus receptor (CAR) is a member of the Ig superfamily strongly expressed in the developing nervous system. Our histological investigations during development reveal an initial uniform distribution of CAR on all neural cells with a concentration on membranes that face the margins of the nervous system (e.g., the basal laminae and the ventricular side). At more advanced stages, CAR becomes downregulated and restricted to specific regions including areas rich in axonal and dendritic surfaces.

To study the function of CAR on neural cells, we used the fiber knob of the adenovirus, extracellular CAR domains, blocking antibodies to CAR, as well as CAR-deficient neural cells. Blocking antibodies were found to inhibit neurite extension in retina organ and retinal explant cultures, whereas the application of the recombinant fiber knob of the adenovirus subtype Ad2 or extracellular CAR domains promoted neurite extension and adhesion to extracellular matrices.

We observed a promiscuous interaction of CAR with extracellular matrix glycoproteins, which was deduced from analytical ultracentrifugation experiments, affinity chromatography, and adhesion assays. The membrane proximal Ig domain of CAR, termed D2, was found to bind to a fibronectin fragment, including the heparin-binding domain 2, which promotes neurite extension of wild type, but not of CAR-deficient neural cells. In contrast to heterophilic interactions, homophilic association of CAR involves both Ig domains, as was revealed by ultracentrifugation, chemical cross-linking, and adhesion studies. The results of these functional and binding studies are correlated to a U-shaped homodimer of the complete extracellular domains of CAR detected by x-ray crystallography.

\section{Introduction}

The coxsackievirus-adenovirus receptor (CAR) was originally identified as a cell-surface protein, which enables group B coxsackieviruses and the adenoviruses of different groups to attach to the surface of cells (Bergelson et al., 1997; Tomko et al., 1997). CAR is a type I transmembrane protein composed of two Ig domains, a membrane distal D1 and a membrane proximal D2, followed by a hydrophobic membrane-spanning region and a cytoplasmic segment that is implicated in basolateral sorting (Cohen et al., 2001a). Together with the junctional adhesion molecules (JAMs), CAR forms a structural subgroup within the Ig superfamily (Weber et al., 2007).

The expression of CAR is developmentally regulated, and its tissue localization is complex (Freimuth et al., 2008). In epithelial

\footnotetext{
Received Nov. 18, 2009; revised Dec. 21, 2009; accepted Jan. 11, 2010.

This work was supported by Deutsche Forschungsgemeinschaft Grants Ra424/5-1 (F.G.R.) and Kr1039/7 (S.K.) and by a Max-Delbrück-Centrum für Molekulare Medizin (MDC) Ph.D. stipend (C.P.). We thank Drs. Paul Freimuth (Brookhaven National Laboratory, Upton, UK), George Santis (King's College, London, UK), and Davide Comoletti and Palmer Taylor (University of California San Diego, La Jolla, CA) for cDNAs encoding fiber knobs Ad2, Ad2C428N, and Ad5 or the LNS domain of $\beta 1$ neurexin, respectively. We acknowledge the help of Dr. Eva-Christina Müller (MDC, Berlin, Germany) with mass spectrometry analysis, of Dr. Elisabeth Pollerberg (University of Heidelberg, Heidelberg, Germany) with the chick retina organ cultures, and of the rotation student Anneke Telkamp for performing adhesion assays. We are grateful to Drs. Carmen Birchmeier, Oliver Daumke, Michael Gotthardt, and Ewan Smith (all from $M D C$, Berlin, Germany) for critical reading of this manuscript.

Correspondence should be addressed to Fritz G. Rathjen, Developmental Neurobiology Group, Max-DelbrückCentrum für Molekulare Medizin, 13092 Berlin, Germany. E-mail: Rathjen@mdc-berlin.de.

DOI:10.1523/JNEUROSCI.5725-09.2010

Copyright $\odot 2010$ the authors $\quad 0270-6474 / 10 / 302897-14 \$ 15.00 / 0$
}

cells, CAR is concentrated at the basolateral membrane of intercellular junctions where it acts as a component of the tight junctional complex through association with ZO-1 (Cohen et al., 2001b) or Mupp-1 (Coyne et al., 2004). When adenovirus fibers that interact with CAR are applied to the basal surface of polarized epithelial cells, intercellular adhesion junctions are disrupted (Walters et al., 2002). In the adult heart, CAR is predominantly localized at the intercalated discs (Shaw et al., 2004). In the vertebrate nervous system, CAR is strongly expressed during embryogenesis, followed by drastic reduction at early postnatal stages (Xu and Crowell, 1996; Honda et al., 2000; Dorner et al., 2005).

The absence of CAR in mice results in lethality at embryonic day 11 because of malformations of the heart (Asher et al., 2005; Dorner et al., 2005; Chen et al., 2006). In the adult heart, ablation of CAR results in disturbed conduction of electrical activity from the atrium $(\mathrm{A})$ to the ventricle $(\mathrm{V})$ as indicated by a prolonged $\mathrm{PR}$ interval in electrocardiogram plots. Deletion of CAR also affects the localization and expression of connexin 45 at the atrioventricular node cell-cell junction, as well as the localization of $\beta$-catenin and ZO-1 at the ventricular intercalated disc (Lim et al., 2008; Lisewski et al., 2008). When expressed in heterologous cells, CAR promotes homotypic cell adhesion (Honda et al., 2000). Overexpression of CAR also increases transepithelial resistance (Excoffon et al., 2004). These studies indicate that CAR may have a function in cell adhesion; however, its precise role in the developing nervous system is unknown. In particular, 
there is no structure-function correlation of the extracellular part of CAR.

Here, we used adhesion and neurite outgrowth assays in the presence of the adenovirus fiber knob, blocking antibodies, extracellular domains of CAR, or CAR-deficient neural cells to study the function of CAR on neural cells. Binding studies demonstrate that CAR engages in a homophilic but also in a heterophilic manner with extracellular matrix (ECM) glycoproteins to promote adhesion and neurite extension. The heterophilic binding involved the D2 domain, whereas homophilic interactions are mediated by both D1 and D2 Ig domains. Crystallographic studies on the complete extracellular region of CAR revealed a $\mathrm{U}$-shaped homodimer, which is stabilized by the N-terminally located D1 domains. Our data provide novel insights into the conformation and molecular interactions of CAR on neural cells.

\section{Materials and Methods}

Retina organ cultures and basal lamina preparation. Eyes of embryonic day 4.5 (E4.5) chicken embryos were isolated, and connective tissue and pigment epithelium were removed in Hank's buffer (Invitrogen), leaving lens, vitreous, retina, and optic nerve intact, and cultured in DMEM/F-12 supplemented with $10 \%$ FCS, $2 \%$ chick serum, and $50 \mu \mathrm{g} / \mathrm{ml}$ gentamycin (all from Invitrogen) for $20 \mathrm{~h}$. Eyes were incubated with anti-CAR Fabs and anti-F11 Fabs, or left untreated. After cultivation, lens and vitreous were removed, and the retina was flat mounted on a nitrocellulose filter (Schleicher and Schuell), where it was fixed for $1 \mathrm{~h}$ in $4 \%$ formaldehyde and stained by an antibody to chL1. Basal lamina preparation of chick retinae and growth of retinal explants were conducted as described previously (Halfter et al., 1987).

Adhesion and neurite outgrowth assays. E8 retinal, E6 tectal, and E6 telencephalic cells from white leghorn chicken embryos, or E11 mesencephali from mouse wild-type or CAR-deficient embryos, were obtained by incubation with $1 \mathrm{mg} / \mathrm{ml}$ trypsin in HBSS for $20 \mathrm{~min}$ at $37^{\circ} \mathrm{C}$. Tissues were rinsed in DMEM, dissociated in DMEM $/ 10 \% \mathrm{FCS}$, and rinsed again in DMEM, and cells were seeded at a density of $50,000 \mathrm{cells} / \mathrm{cm}^{2}$ in tissue culture dishes (Petriperm, Greiner) in DMEM/N2 (Invitrogen) or DMEM/B27 supplemented with penicillin/streptomycin. The dishes were precoated with LN-1 (10 $\mu \mathrm{g} / \mathrm{ml}$; Invitrogen), fibronectin (FN; 5 $\mu \mathrm{g} / \mathrm{ml}$ ), or FN fragment FN40 $(10 \mu \mathrm{g} / \mathrm{ml})$ (see supplemental Fig. S2, available at www.jneurosci.org as supplemental material, and Fig. $4 E$ ) for $12 \mathrm{~h}$ at $4^{\circ} \mathrm{C}$, washed with DMEM, and blocked with BSA/HBSS $(5 \mathrm{mg} / \mathrm{ml})$ for $45 \mathrm{~min}$ at $37^{\circ} \mathrm{C}$. In the case of mouse CAR-D1D2 (mCAR-D1D2; 50 and $100 \mu \mathrm{g} / \mathrm{ml}$ ), precoating with a drop of $2 \mu$ in the center of the culture dish occurred for $45 \mathrm{~min}$ at $37^{\circ} \mathrm{C}$. Cultures were incubated (chicken cells in DMEM/N2 or mouse cells in DMEM/B27) for 24 or $48 \mathrm{~h}$ at $37^{\circ} \mathrm{C}$ in the presence or absence of CAR domains or antibodies in solution. Polyclonal antibodies were applied as Fab fragments $(250 \mu \mathrm{g} / \mathrm{ml})$, and monoclonal antibodies were applied as IgG $(10 \mu \mathrm{g} / \mathrm{ml})$. To count attached cells, nuclei were labeled with the DNA-staining reagent $\mathrm{H} 33258$ after formaldehyde (3.7\% in PBS) fixation. Neurite outgrowth and the number of attached cells were quantified using the software ITEM (Olympus) from at least six images of each experimental condition, conducted at least three times. Both chick CAR (chCAR)-transfected NIH 3T3 and parental cells were incubated in DMEM for 16 to $24 \mathrm{~h}$ at $37^{\circ} \mathrm{C}$. Images $(870 \times 690 \mu \mathrm{m})$ were taken randomly from the culture dish. Data were either normalized to the number of attached cells obtained under control experimental conditions or were expressed per view field as means \pm SEM. The counting was performed blind with regard to the experimental condition or genotype. Statistical significance of differences was evaluated using the Mann-Whitney $U$ test, implemented in the Statview program (Abacus Concepts). Genotyping of CAR-deficient mice has been described previously (Dorner et al., 2005).

Expression and purification of proteins. GST-fusion proteins were obtained by insertion of cDNAs encoding mCAR-D1D2, mCAR-D1, mCAR-D2, or chCAR-D2 (residues given in parentheses; see below) into the expression vector pGEX-6P-1 and expressed in E. coli strain BL21 (GE Healthcare) by standard procedures. Cell pellets were resuspended in $8 \mathrm{~m}$ urea in PBS containing $1 \mathrm{~mm}$ dithiothreitol, $1 \%$ deoxycholate, and protease inhibitors ( $5 \mathrm{~mm}$ pepstatin $\mathrm{A}, 5 \mathrm{~mm}$ leupeptin, $20 \mathrm{U} / \mu \mathrm{l}$ aprotinin, $100 \mathrm{~mm}$ phenylmethyl sulfonyl fluoride). The solution was cleared by centrifugation and dialyzed extensively against PBS to allow refolding of the Ig domains. Precipitated proteins were removed by centrifugation, and the clear solution was passed over glutathione-Sepharose $4 \mathrm{~B}$. The columns were washed with PBS, and GST-fusion proteins were cleaved by PreScission Protease (GE Healthcare). The CAR domain(s) was recovered and further purified by anion exchange chromatography (Mono Q; GE Healthcare) and/or gel filtration (Superdex 200; GE Healthcare) followed by dialysis against PBS or DMEM.

For the generation of eukaryotic proteins, cDNA encoding the two extracellular mouse or chCAR domains were cloned into expression vectors (pIg for chCAR-D1D2 and pIg + for mCAR-D1D2) and transfected into COS-7 cells. The vectors permit expression of the extracellular domains as an Fc fusion protein secreted into the supernatant from which proteins were affinity purified by protein A-Sepharose CL 4B (GE Healthcare). These were termed chCAR-D1D2-Fc or mCAR-D1D2-Fc. To remove the Fc portion, fusion proteins were treated with factor Xa (Roche) (for mouse CAR sequences) or PreScission protease (for chCAR sequences) followed by additional purification using anion exchange chromatography and gel filtration. These proteins were designated mCAR-D1D2-w/oFc or chCAR-D1D2-w/oFc. Complete deglycosylation of chCAR-D1D2-w/oFc occurred by adding PNGaseF (Sigma) for 2 $\mathrm{h}$ at $37^{\circ} \mathrm{C}$. Subsequent anion exchange chromatography separated PNGaseF and deglycosylated chCAR-D1D2-w/oFc.

The purified recombinant proteins were verified by mass spectrometry using a nano-electrospray hybrid quadrupole spectrometer Q-Tof (Waters) (Steen and Mann, 2004). The Mascot software package (Matrix Science) was used for data evaluation.

Primers used to amplify chick or mouse CAR sequences were as follows: chCAR-D1D2-Fc (1-241), 5'-GGGGAATTCATGGAACCGCCGCCGTTG-3' and 5' -GGGGAATTCCAGCTGTATTTATAGGAGG-3'; chCAR-D1D2-w/oFc (1-241), 5'-GGGGAATTCATGGAACCGCCGCCGTTG-3' and 5'-GGGGAATTCCGGGCCCCTGGAACAGAACTTCCAGACCTGTATTTATAGGAGGG-3'; mCAR-D1D2 (20-232), 5' -CACCGGATCCTTGAGCATCACTACACCCG-3' and 5'-GGCTGCGGCCGCGGGTGGGACAACGTC-3'; mCAR-D1 (22-140), 5'-GGGGAATTCATCACTACACCCGAACAGAGG- ${ }^{\prime}$ and $5^{\prime}$-GGGGTCGACTCATCACTTAACAAGAACGGTCAGC-3'; mCAR-D2 (141-237), 5'-GGGGGATCCCCTTCAGGTACAAGATGCTTCG-3' and $5^{\prime}$-GGGGTCGACTCATCATCCGGCTCGGTTGGAGGGTGGG-3'; chCAR-D2 (145-242), 5'-GGGGAATTCCCAGCAAGCACTAAATGCTCCA-3' and 5'-GGGGTCGACACCAGCTGTATTTATAGGAGGG-3'; mCAR-D1D2w/oFc (1-236), 5'-GGGGGTACCATGGCGCGCCTACTGTGCTTCG-3' and 5'-GGGGGATCCCCGGCTCGGTTGGAGGGTGGGAC-3' .

chCAR was purified from detergent extracts of embryonic chicken brain plasma membrane preparations by immunoaffinity chromatography using monoclonal antibody 12-36 (mAb12-36) immobilized to AffiGel 10 (Bio-Rad). Peptide sequences to verify the chCAR amino acid sequence were obtained by Edman degradation of the $36 \mathrm{kDa}$ component of CAR and of tryptic digests of the $36 \mathrm{kDa}$ band of the immunoaffinity isolate of mAb12-36 as detailed previously (Schumacher et al., 1997) (supplemental Fig. S1C, available at www.jneurosci.org as supplemental material). Detergent-resistant complexes of chCAR (at $72 \mathrm{kDa}$ ) were identified by excision of bands from Coomassie-stained SDS-PAGE followed by in-gel digestion with trypsin. The resulting peptide mixture was identified by chromatographic separation on an LC Packings (inner diameter, $75 \mu \mathrm{m}$; length, $150 \mathrm{~mm}$ ) PepMap C18 column (Dionex) using a capillary liquid chromatography system delivering a gradient from 5 to $40 \%$ acetonitrile $/ 0.1 \%$ formic acid. Eluted peptides were ionized by electrospray ionization on a Q-TOF 1 hybrid mass spectrometer (Waters). The mass spectral data were processed into peak lists containing the $\mathrm{m} / \mathrm{z}$ value, charge state of the parent ion, and fragment ion masses and intensities and correlated with the UniProtChicken database using Mascot software (Perkins et al., 1999).

Recombinant agrin was obtained from the supernatant of HEK 293 cells stably transfected with the construct agrin cFull ${ }^{\text {hs }} 7 \mathrm{~A} 4 \mathrm{~B} 8$ or agrin cFull $^{\text {hs }}$ 0A0B0 (Denzer et al., 1995) (here referred to as agrin 7,4,8 and 
agrin $0,0,0)$ and isolated by immunoaffinity chromatography as outlined previously (Mann and Kröger, 1996). The agrin 7,4,8, but not the 0,0,0 isoform, induces acetylcholine receptor aggregation at the neuromuscular junction. Bovine fibronectin (bFN) and FN fragments were obtained from Sigma or Calbiochem (Pierschbacher et al., 1981; Ruoslahti et al., 1981; Penn and Klotz, 1994), and tenascin-R (TN-R) and tenascin-C (TN-C) were purified from chicken brains as described previously (Nörenberg et al., 1992). FN40 was further fractionated by size exclusion chromatography using a Superdex 200 HR column (supplemental Fig. S4, available at www.jneurosci.org as supplemental material).

Expression and isolation of fiber knob Ad2, Ad2C428N, or Ad5 were performed, with slight modifications, as detailed previously (Freimuth et al., 1999; Kirby et al., 2000; Awasthi et al., 2004). The laminin-neurexinsex hormone (LNS) domain of rat neurexin $\beta 1$ was expressed as a GSTfusion protein followed by cleavage of the GST portion using PreScission Protease (GE Healthcare) and further purified by ion exchange chromatography (Comoletti et al., 2003).

Antibodies and immunohistochemistry. Rabbit antisera were raised against GST-mCAR-D1D2 (Rb32), chCAR-D1D2-Fc (Rb54), mCARD1D2-Fc (Rb79), immunoaffinity-purified (by mAb12-36) chCAR from embryonic chicken brain (Rb40), or the $36 \mathrm{kDa}$ band of the immunoaffinity-purified chCAR electroeluted from SDS-PAGE run without reducing agents ( $\mathrm{Rb} 25)$. The IgG fractions were obtained by protein A affinity chromatography and used in Western blots at a concentration of $0.1 \mu \mathrm{g} / \mathrm{ml}$. mAbs to chCAR (mAb12-36 and mAb8-19) were generated in screens to chicken neural proteins by immunizing against electroeluted fractions of detergent extracts of plasma membrane preparations prepared from E15 chicken brains and used in Western blots at a concentration of $1 \mu \mathrm{g} / \mathrm{ml}$ or in immunohistochemistry at $5 \mu \mathrm{g} / \mathrm{ml}$. Secondary antibodies were from Dianova. Fab fragments of rabbit antibodies to chCAR were prepared by mercuri-papain (Sigma) as detailed previously (Porter, 1959). A mAb to contactin1 (Cn1; F11), polyclonal antibodies to chL1, preparation and staining of formaldehyde-fixed tissue sections, and cell adhesion assays have been described previously (Rathjen et al., 1987; Rathjen and Schachner, 1984). Images were obtained at room temperature using an Axiovert 135 microscope (Zeiss) equipped with Neofluar objectives $(5,10,20$, or $40 \times$ magnification with numerical apertures $0.15,0.25,0.5$, or 0.75 , respectively), a CCD camera (Axiocam HRC; Zeiss), and acquisition software (Axiovision 3.1). Contrast and brightness were adjusted in some images using Photoshop (Adobe Systems), but no further processing was performed. Figures were assembled using CorelDraw (Corel).

Chemical cross-linking, copurification of CAR, and blue-native polyacrylamide gel electrophoresis. Chemical cross-linking of recombinant extracellular CAR domains was performed in PBS, pH 8.0, using bis(sulfosuccinimidyl) suberate $\left(\mathrm{BS}^{3}\right.$; Pierce). Cross-linking was started by the addition of $1 \mathrm{~mm}$ (final concentration) $\mathrm{BS}^{3}$ followed by incubation on ice for 1-2 h. Protein concentrations were chosen such that one of the two putative binding partners was used in a molar excess (up to 20 -fold). The reaction was stopped by quenching with $50 \mathrm{~mm}$ Tris$\mathrm{HCl}$ with subsequent heating in Laemmli buffer, SDS-PAGE, and Western blot analysis.

Equal amounts $(\sim 15 \mathrm{mg})$ of FN from bovine plasma, gelatin type A from porcine skin (Sigma), and GST (obtained by expression of pGEX$6 \mathrm{P}-1$ in E. coli BL21) were coupled to cyanogen bromide-activated Sepharose 4B (GE Healthcare) and used as affinity columns. Sepharose $4 \mathrm{~B}$ served as the control. Lysate from detergent extracts of plasma membrane preparations of E15 chick brains (50 mm Tris-HCl, $\mathrm{pH} 7.4,1 \%$ Triton X-100, $150 \mathrm{~mm} \mathrm{NaCl}, 1 \mathrm{~mm} \mathrm{MgCl}_{2}, 1 \mathrm{~mm} \mathrm{CaCl}_{2}, 5 \mathrm{~mm}$ pepstatin A, $5 \mathrm{~mm}$ leupeptin, $20 \mathrm{U} / \mu \mathrm{l}$ aprotinin, and $100 \mathrm{~mm}$ phenylmethyl sulfonyl fluoride) was applied to enrich chCAR. After washing with 5 bed volumes (with $50 \mathrm{~mm}$ Tris- $\mathrm{HCl}, \mathrm{pH} 7.4$, and $150 \mathrm{~mm} \mathrm{NaCl}$ ), identical volumes of eluted fractions ( $0.1 \mathrm{~m}$ diethylamine, $\mathrm{pH} 11.5)$ were further analyzed by Western blotting.

To characterize the oligomeric state of CAR from brain extracts, bluenative $(\mathrm{BN})$ gels, with $4-12 \%$ acrylamide concentration, were prepared with slight modifications and run under conditions as described previously (Schagger and von Jagow, 1991). Eighty micrograms of 3-[(3cholamidopropyl)dimethylammonio]-1-propanesulfonate (CHAPS;
Table 1. Summary of crystal parameters, data statistics, and refinement statistics

\begin{tabular}{|c|c|}
\hline Space group & $P 2_{1} 2_{1} 2$ \\
\hline Unit cell dimensions $(\AA)^{a, d, e}$ & $53.37,61.47,86.36$ \\
\hline Resolution range (total) $(\AA)^{a}$ & $50-2.18$ \\
\hline Resolution range (high) $(\AA)^{a}$ & $2.26-2.18$ \\
\hline$<l / \sigma(l)>(\text { total, high })^{a}$ & $13.62,2.37$ \\
\hline$R_{\text {merge }}{ }^{a, d}$ & $0.08,0.45$ \\
\hline$R_{\text {work }} / R_{\text {free }}(\%)^{b, d}$ & $20.9 / 26.5$ \\
\hline \multicolumn{2}{|l|}{ Content of asymmetric unit ${ }^{b}$} \\
\hline Protein molecules & 1 \\
\hline Protein atoms, non $\mathrm{H}$ & 1647 \\
\hline Water molecules & 127 \\
\hline \multicolumn{2}{|l|}{ Ramachandran statistics ${ }^{c}$} \\
\hline Favored regions (\%) & 96.7 \\
\hline Allowed regions (\%) & 3.3 \\
\hline RMSD bond length $(\AA)^{b}$ & 0.016 \\
\hline RMSD bond angles $\left({ }^{\circ}\right)^{b}$ & 1.483 \\
\hline RMSD planar groups $(\AA)^{b}$ & 0.005 \\
\hline
\end{tabular}

${ }^{a}$ As reported by HKL2000 (Otwinowski and Minor, 1997).

${ }^{b}$ As reported by REFMAC (Murshudov et al., 1997).

'As reported by Molprobity (Lovell et al., 2003).

${ }^{d} R_{\text {merge }}=\frac{\sum|| I_{\text {obs }}|-| I_{\text {avg }}||}{\sum\left|I_{\text {avg }}\right|}$.

${ }^{e} R_{\text {work,free }}=\sum \frac{\left|F_{\text {obs }}\right|-\left|F_{\text {calc }}\right|}{\left|F_{\text {obs }}\right|}$ where the working and free $R$ factors are calculated using the working and free reflection sets, respectively. The free reflections were excluded throughout refinement.

$1 \%)$ extracts of membrane fractions of embryonic chicken tecta were loaded per lane.

Selection of NIH 3 T3 or CHO cell lines stably expressing chCAR. CARnegative NIH 3T3 and $\mathrm{CHO}$ cells were double transfected with pSG5chCAR (encoding complete chCAR) and pWLneo (encoding the neomycin resistance gene NeoR) and selected in DMEM/10\% FCS containing G418 (geneticin) at a final concentration of $200-1000 \mathrm{ng} / \mu \mathrm{l}$. Clones were tested for chCAR expression by indirect immunofluorescence using mAb12-36 and kept as cryostocks.

Analysis of molecular interactions. Molecular mass studies of dissolved proteins were performed in an XL-A-type analytical ultracentrifuge (Beckman) equipped with UV absorbance optics. Sedimentation equilibrium experiments were performed using externally loaded six-channel cells with $12 \mathrm{~mm}$ optical path length and the capacity to handle three solvent-solution pairs of $\sim 70 \mu \mathrm{l}$ liquid. Sedimentation equilibrium was reached after $2 \mathrm{~h}$ of overspeed (e.g., at 20,000 rpm followed by an equilibrium speed of $16,000 \mathrm{rpm}$ for about $30 \mathrm{~h}$ at $10^{\circ} \mathrm{C}$ ). The radial absorbance in each compartment was recorded at three different wavelengths between 220 and $290 \mathrm{~nm}$ depending on the polypeptide concentration used in the experiments. Molecular mass determinations and interaction studies were done using the software POLYMOLE as described previously (Behlke et al., 1997).

Crystallization and structure determination of mCAR-D1D2. mCARD1D2 (residues 20-232) was crystallized by vapor diffusion using the sitting drop method in an automated setup (Heinemann et al., 2003): 400

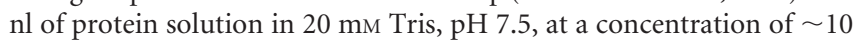
$\mathrm{mg} / \mathrm{ml}$ was mixed with $400 \mathrm{nl}$ of crystallization buffer containing $0.1 \mathrm{M}$ HEPES, pH 7.5, 21\% PEG 4000, and 15\% isopropanol and equilibrated against a reservoir filled with $80 \mu \mathrm{l}$ of crystallization buffer. For freezing, setups containing crystals were overlayed with $2 \mu$ l of fresh crystallization buffer supplemented with $10 \%$ glycerol. Crystals were harvested from the drops and flash frozen in liquid nitrogen. A single $x$-ray diffraction dataset was collected at BL2 of BESSY using a fixed wavelength of $0.9194 \AA$. Data up to $2.18 \AA$ were indexed, integrated, and scaled using HKL2000 (Otwinowski and Minor, 1997). Using phaser (McCoy et al., 2007), the phase problem was solved by molecular replacement using the crystal structures of an isolated D1 domain of human CAR [Protein Data Bank (PDB) accession number 1EAJ] and the third Ig domain of DSCAM (2V5J) as search models. A unique solution was found, and the crystal structure of mCAR-D1D2 was automatically assembled and completed using ARP/wARP as implemented in Ccp4 (Bailey, 1994). The model was 

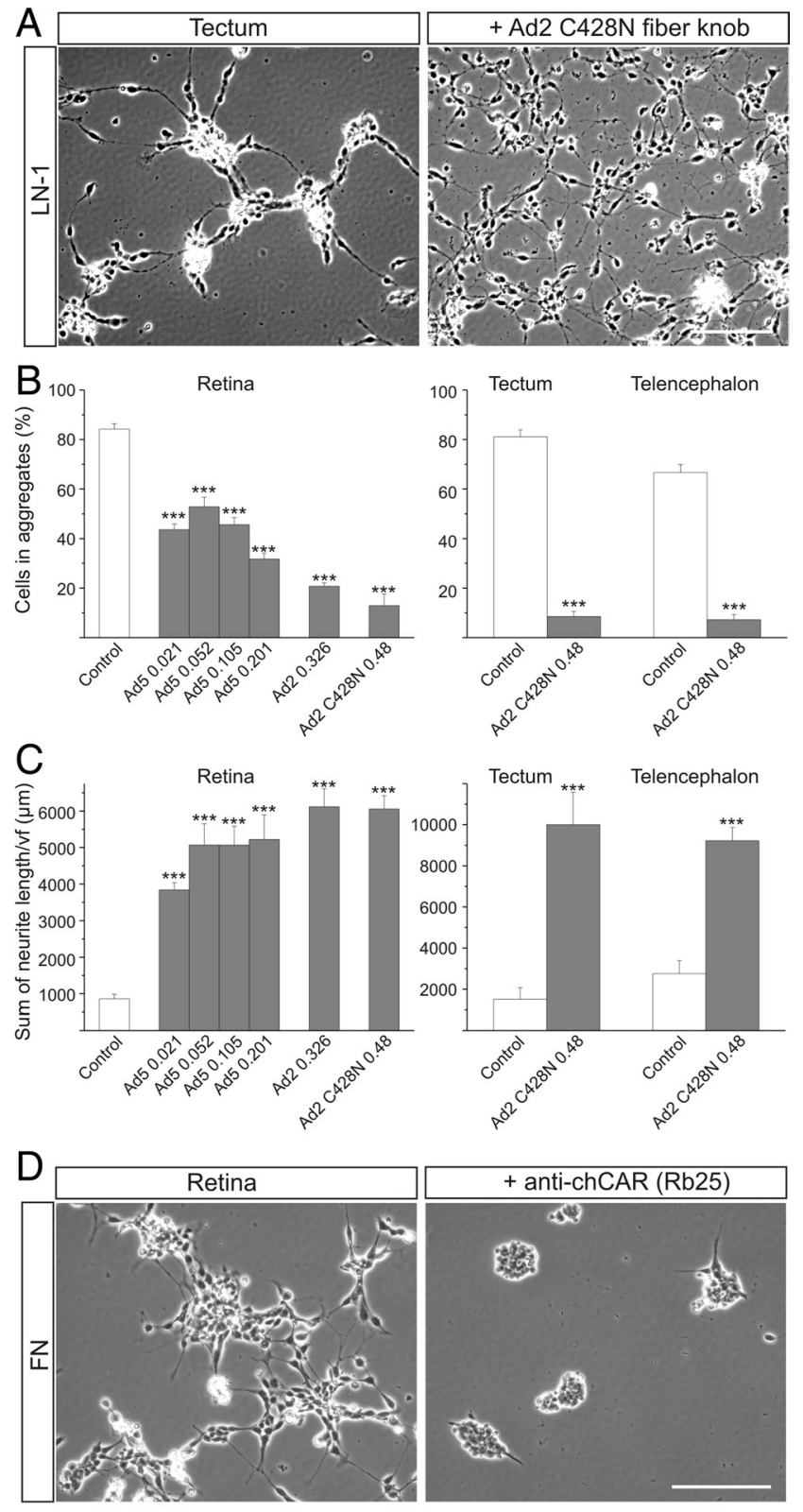

E
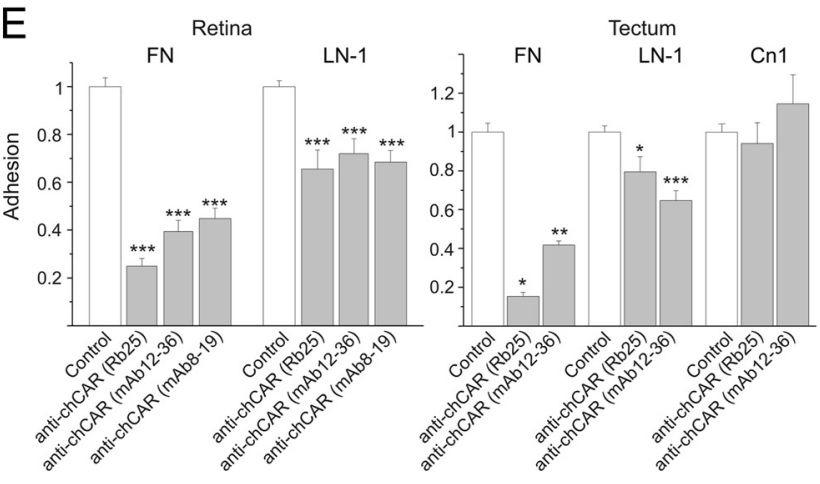

Figure 1. Attachment and neurite extension to ECM glycoproteins in the presence of the fiber knob of the adenovirus or anti-CAR antibodies. $\boldsymbol{A}-\boldsymbol{C}$, In the presence of the fiber knob, the number of single neural cells from chicken embryos (E8) attached and the total length of measurable neurites increased on immobilized LN-1. Clusters of somata of more than five cells were considered as aggregates. Concentrations of fiber knobs ( $\mathrm{Ad2}, \mathrm{Ad2} C 428 \mathrm{~N}, \mathrm{Ad} 5$ ) from different adenoviruses are indicated in milligrams per milliliter. $\boldsymbol{D}, \boldsymbol{E}$, Attachment of retinal cells to $\mathrm{FN}$ or $\mathrm{LN}-1$ is reduced in the presence of antibodies to CAR. The mean number of attached cells in the presence of antibodies to CAR is compared with untreated cells. Polyclonal rabbit antibodies manually revised and extended using $2 F_{\mathrm{o}}-F_{\mathrm{c}}$ and $F_{\mathrm{o}}-F_{\mathrm{c}}$ maps in COOT (Emsley and Cowtan, 2004), followed by cycles of automated refinement using REFMAC (Murshudov et al., 1997). B-factors were refined isotropically. Data and refinement statistics are shown in Table 1. The final structural model was deposited under accession (3JZ7) in the PDB.

Dimerization interfaces and intermolecular interactions were analyzed using PISA (protein interfaces, surfaces, and assemblies service at the European Bioinformatics Institute) (Krissinel and Henrick, 2007) and WHAT IF (Vriend, 1990); structural homologs to D1 and D2 were identified using DALI (Holm and Sander, 1995), and their structural similarities were analyzed using the superposition function of WHAT IF. Sequences of CAR and JAM orthoforms were obtained by Basic Local Alignment Search Tool (BLAST) searches (Altschul et al., 1990) using the protein sequences of human CAR. Sequence conservation in these proteins was analyzed by multiple sequence alignment using ClustalW and mapped to the surface of structural models using ConSurf. The GRAMM-X docking software (Tovchigrechko and Vakser, 2006) was used to detect conserved complementary surfaces in the mCAR-D1D2 structural model, which may enable interactions between D1 and D2. For the search, two copies of the mCAR-D1D2 structure were uploaded, and residues $54,56,121,123,157,200$, and 201 , which are all highly conserved, were included. Intermolecular interfaces of all potential models obtained by this approach were evaluated, and the one featuring the most productive interactions was presented here. All molecular structures in this work were displayed with Pymol (DeLano Scientific).

\section{Results}

Attachment and neurite outgrowth on ECM glycoproteins is promoted by the adenovirus fiber knob and blocked by

\section{anti-CAR antibodies}

To study the function of CAR on neural cells, we used the adenovirus fiber knob and blocking antibodies to CAR in neurite outgrowth and adhesion assays using chicken cells. The fiber knob is a homotrimeric protein of the adenovirus that binds up to three D1 polypeptides (Bewley et al., 1999; Roelvink et al., 1999). In the presence of recombinant fiber knobs from two different adenovirus strains (Ad2, Ad2 C428N, or Ad5), neurite outgrowth on ECM glycoproteins was strongly increased in a concentrationdependent manner (Fig. 1 $A, C$ ). In parallel, the percentage of neural cells in clusters decreased, suggesting that cell-cell interactions are decreased by the fiber knob (Fig. $1 A, B$ ). This was observed using retinal, tectal, or telencephalic cells on several ECM glycoproteins tested including laminin-1 (LN-1) (Fig. 1 A$C$ ), FN (data not shown), TN-C, and TN-R (supplemental Fig. S2, available at www.jneurosci.org as supplemental material).

In contrast to the fiber knob, polyclonal as well as monoclonal antibodies directed against the extracellular portion of chCAR reduced the attachment of neural cells and neurite extension on ECM glycoproteins. The strongest inhibition occurred on immobilized FN, less inhibition occurred on LN-1, and no inhibition occurred on Cn1 (also termed F11), another Ig superfamily member. Polyclonal antibodies were more effective compared with monoclonal antibodies (Fig. $1 D, E$ ). The latter recognizes epitopes on D1, whereas polyclonal antibodies bound to domains D1 and D2 of CAR (supplemental Fig. S1 A, available at www. jneurosci.org as supplemental material).

A reduction in neurite length caused by antibodies was also observed in E4.5 retinal organ cultures (Fig. $2 A, B$ ). This assay selectively assesses the axonal growth of retinal ganglion cells

$\leftarrow$

(Rb25) were applied in the form of Fab fragments ( $0.25 \mathrm{mg} / \mathrm{ml})$ and mAbs as intact lgGs (10 $\mu \mathrm{g} / \mathrm{ml})$. The specificity of the polyclonal antibodies were tested by preincubation with affinitypurified CAR, which resulted in complete neutralization of the antibody-mediated effect. Scale bars, $100 \mu \mathrm{m}$. Error bars indicate SEM. ${ }^{*} p<0.05 ;{ }^{* *} p<0.005 ;{ }^{* * *} p<0.0005$. 
A

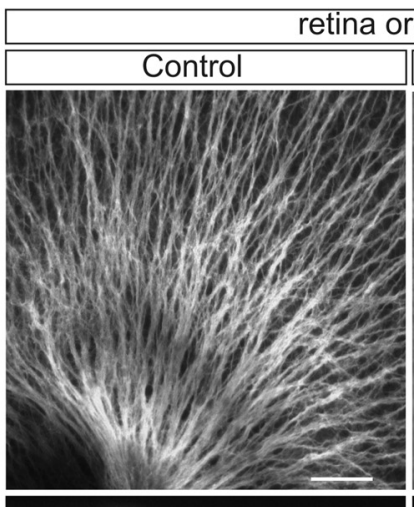

$\mathrm{B}$
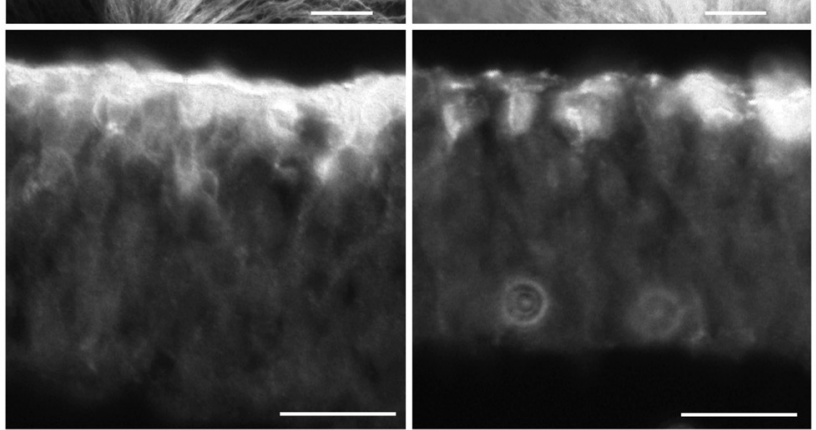

C

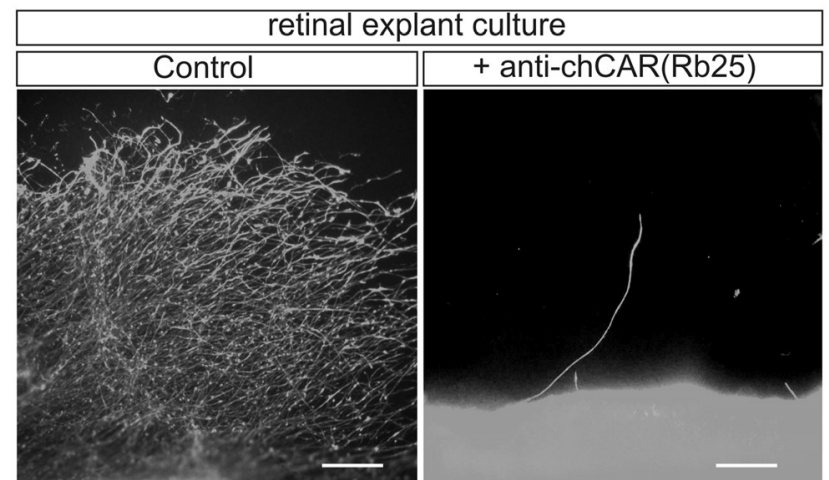

$E$
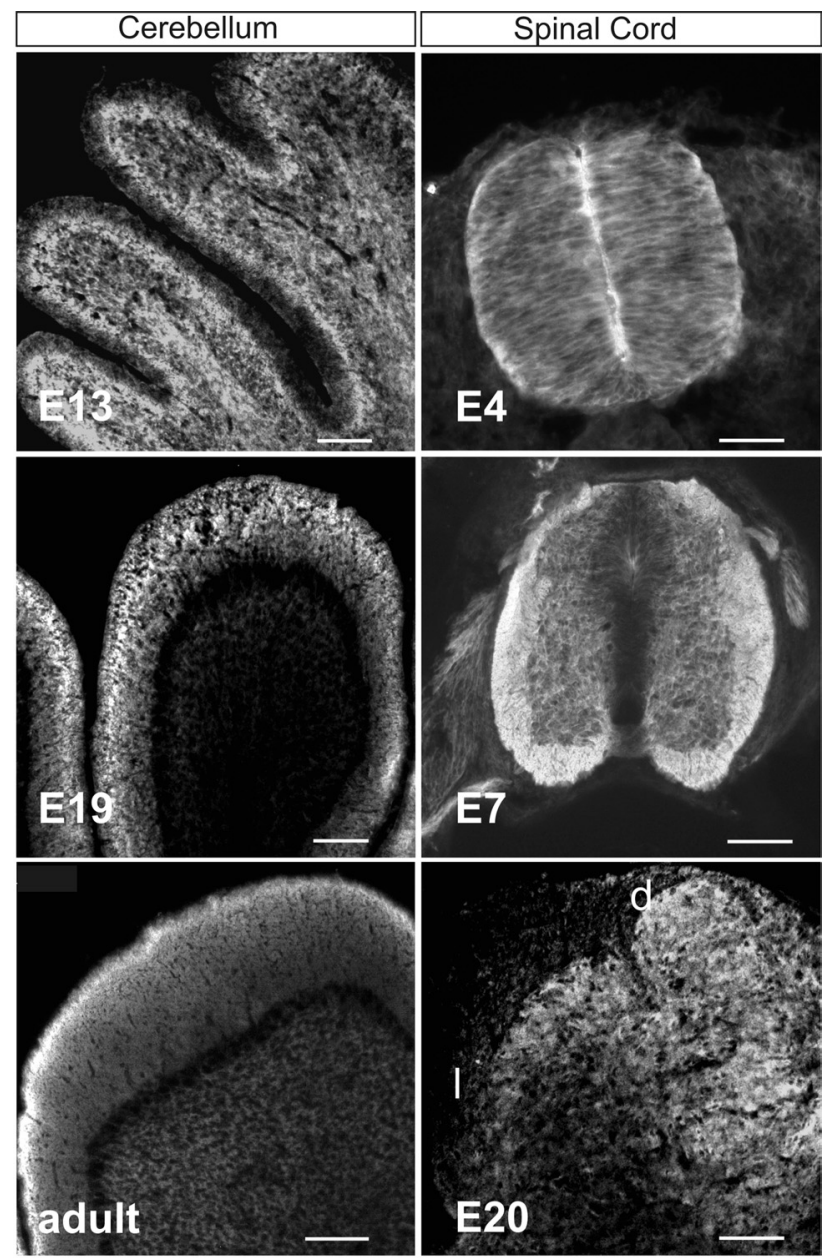
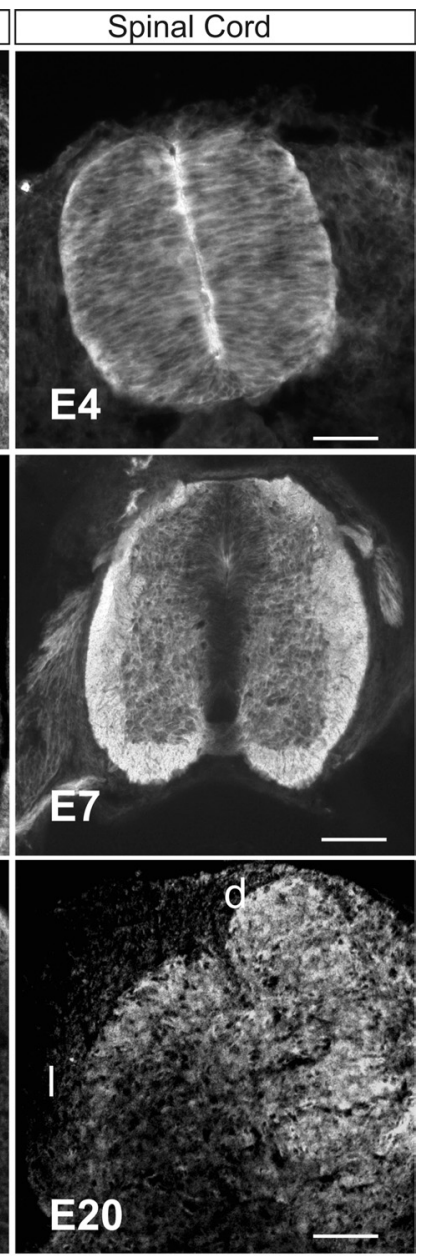

E4
$\mathrm{D}$

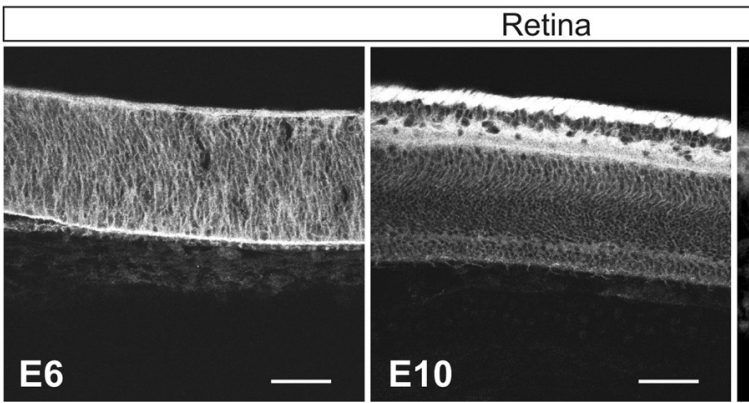

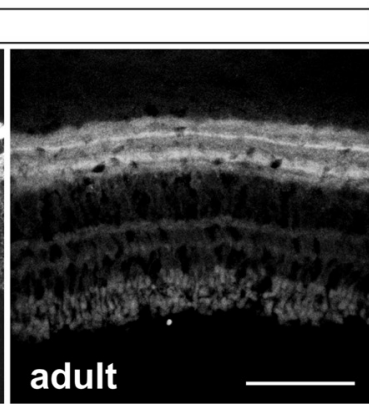

$\mathrm{F}$

Figure 2. The outgrowth of RGC axons in retina organ cultures and on basal laminae is reduced in the presence of antibodies to chCAR. $A$, RGC axons in flat-mounted retina organ cultures in the presence of Fab fragments of polyclonal antibodies to chCAR or control antibodies $(0.5 \mathrm{mg} / \mathrm{mll})$. Chick embryonic eyes (E4.5) were cultivated after removal of the pigment epithelium for $20 \mathrm{~h}$. After fixation, retinae were flat mounted, and RGC axons were visualized by anti-chL1 staining. $\boldsymbol{B}$, (ross sections of retina organ cultures. In the developing optic fiber layer (top), fewer axon bundles of RGCs are observed in the presence of Fab fragments of anti-CAR antibodies. C, E6 retinal explants incubated for $24 \mathrm{~h}$ on basal laminae preparations from chick retinae in the presence of Fab fragments of polyclonal antibodies to chCAR ( $0.5 \mathrm{mg} / \mathrm{ml}$ ) or control antibodies. D, Localization of CAR in the developing chick retina. Cryostat sections of E6, E10, or adult retinae were stained indirectly by mAb12-36 to chCAR. OFL, Optic fiber layer; IPL, inner plexiform layer; INL, inner nuclear layer; OPL, outer plexiform layer; PhR, photoreceptor layer. E, Localization of CAR in cryostat sections of chicken cerebellum or spinal cord at different developmental stages using mAb12-36. The E20 spinal cord section shows only the dorsolateral half of the cord. $\boldsymbol{F}$, Western blot analysis of the chick retinae from different developmental stages (E7-E20) using mAb12-36. Note that in contrast to CAR, Cn1 is upregulated during development. Lanes were loaded with equal amounts of protein $(5 \mu \mathrm{g})$. G, A developmental gradient of CAR within the retina is revealed by Western blotting. The E16 retina was cut into three parts: central (C), intermediate (I), or peripheral (P) retina. Equal amounts of protein from each part was loaded on SDS-PAGE and analyzed in Western blots using mAb12-36. Scale bars, $100 \mu \mathrm{m}$.

(RGCs) (Halfter and Deiss, 1986; Pollerberg and Beck-Sickinger, 1993). After $20 \mathrm{~h}$ of cultivation in the presence of anti-CAR antibodies, retinae were flat mounted and stained with an antibody to chL1 to visualize RGC axons. Because of a temporal gradient of development that extends from the central to the peripheral ret- ina, thin axon bundles converge to increasingly thicker fascicles toward the optic fissure, as indicated by the appearance of thinner fascicles that was observed in the presence of anti-CAR antibodies in whole-mount preparations, which might be caused by a reduction in axon growth or defasciculation (Fig. $2 \mathrm{~A}$ ). However, cross 
sections of the organ culture indicated that fewer axons extended in the optic fiber layer (Fig. 2B). When basal lamina preparations from embryonic retinae (Halfter et al., 1987) were used as substrate for retinal explants, an almost complete block of neurite extension of RGC axons was apparent in the presence of polyclonal antibodies to chCAR (Fig. 2C). Thus, reagents that bind selectively to CAR and interfere with its function also modulate the attachment and/or neurite extension of cultured neural cells, suggesting an interaction of CAR with various ECM glycoproteins.

\section{CAR localization in the developing retina is dynamically regulated} Consistent with a function of CAR in the extension of RGC axons is the localization of CAR. In agreement with previous studies (Xu and Crowell, 1996; Honda et al., 2000), we detected CAR on all neural cells in sections of the retina. However, CAR was enriched at specific sites, including a strong localization on RGC axons facing the vitreous body, suggesting that CAR might mediate an interaction of RGC axons with ECM proteins of the inner limiting membrane, or with other RGC axons. Cellular structures facing the pigment epithelium were also strongly stained for CAR (Fig. 2D). At advanced developmental stages, the total amount of CAR that migrates as a $46 \mathrm{kDa}$ band in SDS-PAGE decreased in the retina with a central-toperipheral gradient (Fig. $2 F, G$ ), and CAR became concentrated in the inner plexiform layer of the retina where it remains detectable at adult stages (Fig. 2D). Changes in the developmental expression profile for CAR were also detected in the cerebellum and the spinal cord (Fig. 2E).

\section{CAR is found in protein complexes in neural membranes}

In size-exclusion chromatography, CAR migrated in the molecular mass range of $50-900 \mathrm{kDa}$ with a peak at $240 \mathrm{kDa}$ (Fig.

$3 A$ ) and in $\mathrm{BN}$ gel electrophoresis from 200 to $1000 \mathrm{kDa}$ with a peak at $600 \mathrm{kDa}$ (Fig. 3B). These findings suggest that CAR forms multimeric complexes on neural cells by self-association, or by binding to other proteins. Furthermore, SDS-resistant complexes were observed in immunoaffinity isolates of CAR from detergent extracts of plasma membrane preparations of embryonic chicken brain. In addition to the major CAR components at 46 and $36 \mathrm{kDa}$, several higher molecular mass components were detected whose identities were identified by mass spectrometry and Western blotting as CAR (Fig. 3C). Consistent with CAR being part of high molecular mass complexes, CAR is found in a punctuate pattern on the surface of growth cones, neurites, and the soma of cultivated neurons (Fig. 3D). Arbitrary units.
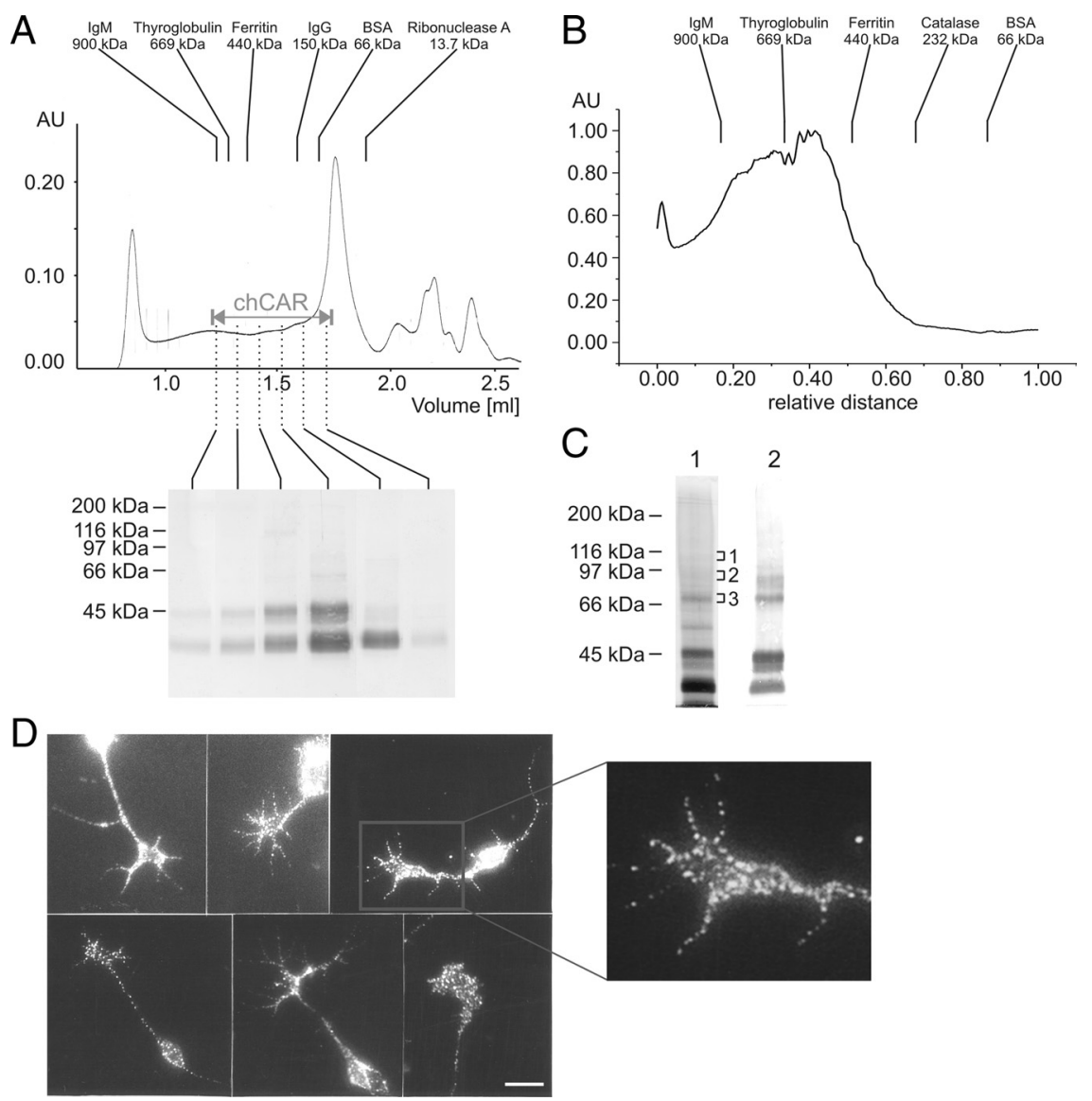

Figure 3. CAR exists in protein complexes on neural surfaces. A-C,CAR from chicken brain exists in complexes as analyzed by ge Iltration or BN gels. Detergent (1\% CHAPS) extracts of plasma membrane preparations from embryonic chicken brains were run acrylamide were blotted, and a densitometric scan of the Western blot using Rb54 is shown. [Note that CAR purified from detergent extracts by immunoaffinity or gel filtration chromatography consists of two major components at 36 and $46 \mathrm{kDa}$. The $36 \mathrm{kDa}$ suggesting that it results from C-terminal degradations of CAR.] Molecular masses of standard proteins are given at the top or on pres embryonic chicken brains reveals SDS-resistant complexes in SDS-PAGE under reducing conditions as visualized by silver staining (lane 1). Lane 2 shows a Western blot analysis of the affinity isolate as revealed in lane 1 using Rb54 to chCAR. In the 36 and $46 \mathrm{kDa}$ bands, minor components at 72, 95, and $110 \mathrm{kDa}$ were also detected. The identity of these proteins was further established by mass spectrometry sequencing of a tryptic digest that yielded chCAR peptides encompassing the following amino acid residues (the position are given): $72 \mathrm{kDa}(3): 71-82,72-82,83-94,95-103,104-115,128-136,150$ $66-180,181-197,182-192,210-222,277-290,305-320,321-333,354-366 ; 110 \mathrm{kDa}(1): 71-82,72-82,95-103,104-$ $15,128-136,166-180,182-197,210-222,305-320,321-333,354-366$. D, Localization of CAR on chick tectal neuron cultivated on LN-1. CAR was stained after fixation using mAb12-36. One growth cone is enlarged on the right. Scale bar, $20 \mu \mathrm{m}$. AU,

\section{D2 of CAR binds to the heparin binding domain 2 of FN}

The above-described modulation of neurite extension by antiCAR antibodies and by the fiber knob suggested that CAR might interact directly with ECM glycoproteins. Therefore, recombinant extracellular CAR domains (supplemental Fig. S1 B, available at www.jneurosci.org as supplemental material) were tested for their ability to self-associate or to interact with ECM glycoproteins. We generated fusion proteins of the Fc portion of human IgG1 with the extracellular sequences of chick or mouse CAR (designated chCAR-D1D2-Fc or mCAR-D1D2-Fc). For some experiments, the $\mathrm{Fc}$ portion was removed from the fusion protein by proteolytic digestion, followed by purification of the CAR polypeptide (termed chCAR-D1D2-w/oFc or mCAR-D1D2-w/ $\mathrm{oFc})$. For mapping of binding regions, extracellular domains of 
CAR were generated in bacteria (termed mCAR-D1D2, mCAR-D1, mCAR-D2, or chCAR-D2). Binding analysis was primarily performed by sedimentation equilibrium analysis, a solution-based technique that removes the effects of protein immobilization.

Since anti-CAR antibodies interfered most strongly with the adhesion of neural cells to FN, binding studies were initially conducted with intact FN. chCAR-D1D2-Fc, mCAR-D1D2-w/oFc, and mCAR-D1D2 were found to interact with FN in the $10^{-7} \mathrm{M}$ range (Fig. 4, Table 2). In these experiments, CAR concentrations were used at which self-association of CAR is minimal or does not occur at all (see Figs. 6, 8). Overall, the CAR FN affinity was in the range of the fiber knob CAR interaction (Fig. 4A, Table 2).

To characterize the CAR FN binding further, fragments generated by limited proteolysis of FN and previously mapped in adhesion assays (Pierschbacher et al., 1981; Ruoslahti et al., 1981; Penn and Klotz, 1994) were tested for binding to mCAR-D1D2. Both the 30 and $40 \mathrm{kDa}$ fragments of FN (FN30 or FN40) encompassing the heparin-binding domain 2 (see supplemental Fig. $\mathrm{S} 3 A-C$, available at www.jneurosci.org as supplemental material, for further characterization) were found to interact with mCARD1D2 (Fig. 4B), whereas neither the $70 \mathrm{kDa}$ (FN70) nor the 120 $\mathrm{kDa}$ (FN120) fragment did (Table 2, Fig. 4E). mCAR-D2 was sufficient to bind to FN (Fig. 4C), or to FN40, whereas mCAR-D1 did not (Table 2). The fact that the bound ratios reach numbers higher than 1 indicates that more than one CAR polypeptide binds to the FN dimer (Fig. $4 A, C$ ). In contrast, only one CAR polypeptide interacts with monomeric FN30 or FN40 (Fig. $4 B$ ). Independent experimental support for the interaction between CAR and FN is provided by affinity chromatography (Fig. 4D). CAR could be enriched on an FN but not on a GST or gelatin affinity column using detergent extracts of embryonic chicken brain plasma membranes.

To obtain additional evidence for the interaction between CAR and FN, neurite outgrowth assays using wild-type or CAR-deficient cells from day 11 mouse embryos were performed. Since the multidomain protein $\mathrm{FN}$ is recognized by multiple cellular receptors, the FN40 fragment was used as an immobilized substrate. Neurite outgrowth and aggregation was reduced by CAR-deficient cells (Fig. $5 A, B)$. Similarly, antibodies to chCAR but not to chL1 interfered with neurite extension of chick tectal neurons (Fig. $5 C, D$ ) and blocked the formation of cell clusters on FN40 (Fig. 5C,D).

\section{Interactions between CAR and TN-R, LN-1, or agrin}

Since reagents binding to CAR also modulate neural adhesion to ECM glycoproteins other than FN (Fig. 1E), we applied equilibrium sedimentation to test whether chCAR-D1D2-Fc or mCAR-D1D2 were able to bind to these proteins. The binding studies revealed a complex formation between chCAR-D1D2-Fc and TN-R, LN-1, agrin-7,4,8 or agrin- $0,0,0$ with dissociation constants in the $10^{-7} \mathrm{M}$ range (Fig. $4 F-I$, Table 2). In contrast, no interaction was detected between mCAR-D1D2 and the LNS domain of $\mathrm{r} \beta 1$-neurexin.

In summary, on the basis of binding and adhesion assays, we conclude that the extracellular portion of CAR binds to the ECM glycoprotein FN, LN-1, TN-R, or agrin. The D2 domain of CAR is required for the interaction with FN, specifically with the fragments FN40 or FN30.

\section{The extracellular domains of CAR are self-associating and mediate homotypic aggregation}

Previous studies reported that CAR mediates homotypic cell aggregation of transfected cells in the presence of FCS, which contains dimeric FN (Honda et al., 2000). To investigate whether this homotypic aggregation is mediated by a homophilic or hetero-
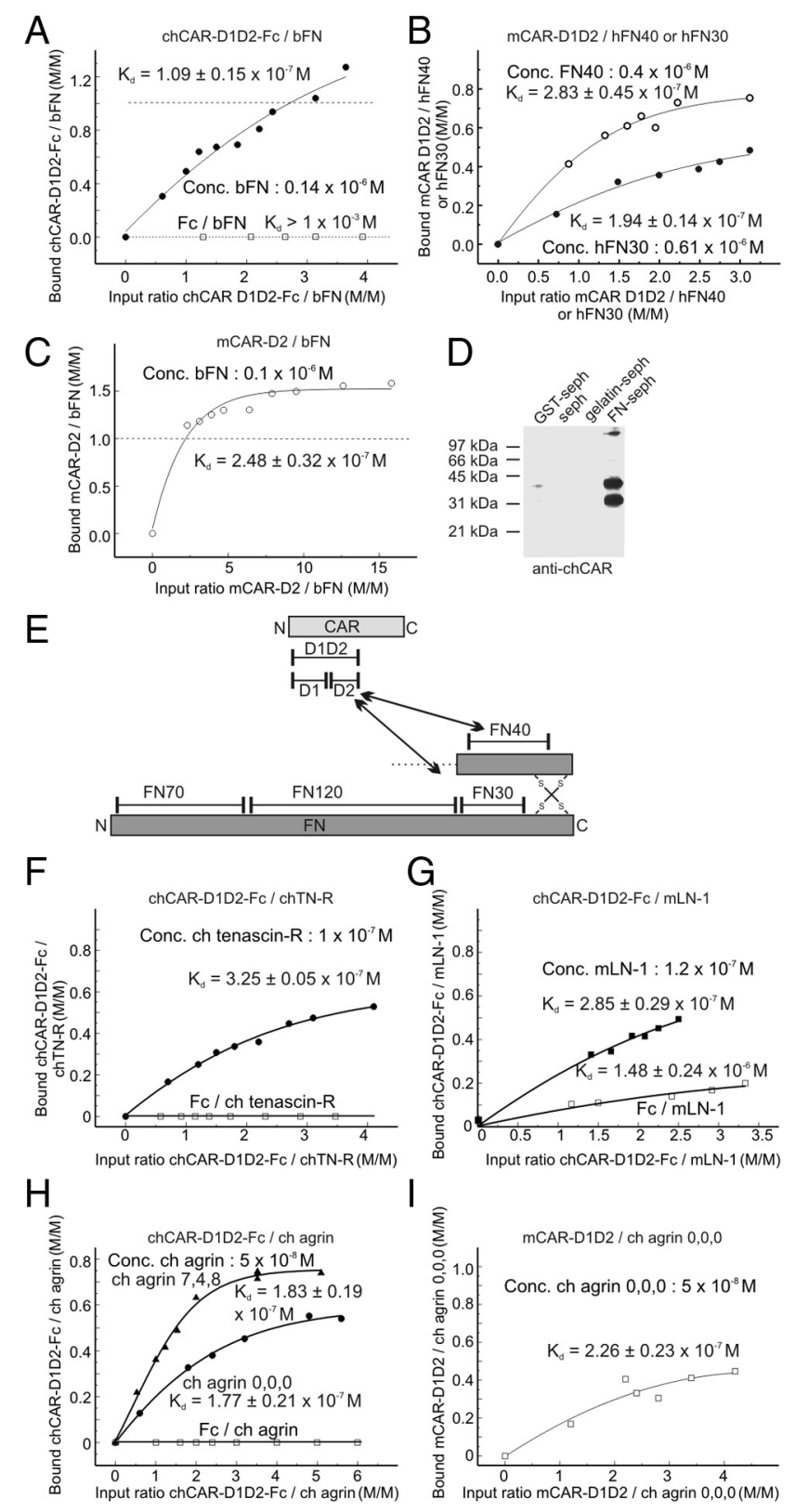

Figure 4. D2 of CAR binds to FN, FN30, or FN40, and CARinteracts with the ECM glycoprotein TN-R, LN-1, or agrin. $A$, Equilibrium sedimentation of chCAR-D1D2-Fc and bFN. Note that at a 3.5-fold molar excess of chCAR-D1D2-Fc, more than one chCAR-D1D2-Fc is bound to FN. The Fc fragment served as the control. A concentration of $0.14 \mu \mathrm{m}$ chCAR-D1D2-Fc corresponds to $16.9 \mu \mathrm{g} / \mathrm{ml}$. B, mCAR-D1D2 binds to the fragment FN40 or FN30 (see also supplemental Fig. S3, available at www.jneurosci.org as supplemental material). A concentration of $0.4 \mu \mathrm{m}$ mCAR-D1D2 corresponds to $9.6 \mu \mathrm{g} / \mathrm{ml}$. C, Interaction of mCAR-D2 and FN is demonstrated by equilibrium sedimentation. A concentration of $0.1 \mu \mathrm{m}$ mCAR-D2 corresponds to $1.2 \mu \mathrm{g} / \mathrm{ml}$. D, chCAR enriched on a FN-Sepharose (seph) column. Equal volumes of detergent extracts of plasma membrane preparation from E15 chicken brains were passed over different affinity columns, washed, and eluted by diethylamine at $\mathrm{pH} 11.5$, followed by Western blotting. chCAR appears under nonreducing conditions as bands of 42 and $32 \mathrm{kDa}$ (see also Fig. 3C).E, Scheme of the CAR-FN interaction. Locations of the FN fragments and the N or Ctermini are indicated. Only a part of the two polypeptides of a FN dimer is shown. $F-I$, Equilibrium sedimentation analyses of interactions between chCAR-D1D2-Fc and TN-R, LN-1, and of the splice variants of agrin $0,0,0$ or 7,4,8, and between mCAR-D1D2 and agrin 0,0,0. The Fc fragment served as the control. Conc., Concentration.

philic binding mode, cell adhesion to, and self-associations of, the complete extracellular CAR domains were tested.

Here, we show that stably chCAR-expressing cells obtained by transfection attached and spread on mCAR-D1D2, in contrast to 
Table 2. Dissociation constants of the heterophilic molecular interactions of CAR

\begin{tabular}{|c|c|c|c|c|c|c|}
\hline$\overline{K_{d}(M)}$ & chCAR-D1D2-Fc & $\mathrm{Fc}$ & mCAR-D1D2-w/oFc & mCAR-D1D2 & mCAR-D1 & mCAR-D2 \\
\hline Fiber knob Ad2 & $1.4 \pm 0.1 \times 10^{-7}$ & $1.65 \pm 0.32 \times 10^{-4}$ & & $4.2 \pm 0.3 \times 10^{-7}$ & $2.4 \pm 0.2 \times 10^{-7}$ & No binding \\
\hline bFN & $1.09 \pm 0.15 \times 10^{-7}$ & $>10^{-3}$ & $1.67 \pm 0.21 \times 10^{-7}$ & $1.87 \pm 0.18 \times 10^{-7}$ & No binding & $2.48 \pm 0.32 \times 10^{-7}$ \\
\hline hFN120 & & & & No binding & & \\
\hline hFN70 & & & & No binding & & \\
\hline hFN40 & & & & $2.83 \pm 0.45 \times 10^{-7}$ & & $1.53 \pm 0.29 \times 10^{-6}$ \\
\hline hFN30 & & & & $1.94 \pm 0.14 \times 10^{-7}$ & & \\
\hline$m L N-1$ & $2.85 \pm 0.29 \times 10^{-7}$ & $1.48 \pm 0.24 \times 10^{-6}$ & & & & \\
\hline chTN-R & $3.25 \pm 0.05 \times 10^{-7}$ & No binding & & & & \\
\hline ch agrin 7,4,8 & $1.83 \pm 0.19 \times 10^{-7}$ & No binding & & & & \\
\hline ch agrin $0,0,0$ & $1.77 \pm 0.21 \times 10^{-7}$ & No binding & & $2.26 \pm 0.23 \times 10^{-7}$ & & \\
\hline $\mathrm{r} \beta 1$-neurexin LNS domain & & & & No binding & & \\
\hline
\end{tabular}

CAR-negative parental cells (Fig. 6E). Antibodies that bind to cellular chCAR, but not to immobilized mCAR-D1D2, interfered with the adhesion of chCAR-expressing NIH 3T3 or tectal cells (Fig. $6 F$ ), indicating that cellular chCAR interacts with immobilized domains of mCAR (see also supplemental Fig. S4 A, B, available at www.jneurosci.org as supplemental material).

Consistent with the cell-attachment assay, self-associations were found between polypeptides composed of the complete extracellular region of CAR in sedimentation analysis. However, the affinities between the different recombinant proteins differed markedly. Prokaryotic mCAR-D1D2 formed a concentration-dependent monomer-dimer equilibrium with a low affinity $\left(K_{\mathrm{d}}=1.4 \pm 0.2 \times 10^{-4} \mathrm{M}\right)$. The majority of molecules were in a monomeric state up to a concentration of $2 \mathrm{mg} / \mathrm{ml}$ (Fig. 6A). In contrast, eukaryotically expressed mCAR-D1D2-w/oFc formed dimers at about 10-fold lower concentrations with $K_{\mathrm{d}}=3.89 \pm 0.27 \times 10^{-6} \mathrm{M}$. Already at a concentration of $170 \mu \mathrm{g} / \mathrm{ml}, 50 \%$ of mCAR-D1D2-w/oFc polypeptides were found in a dimeric state (Fig. $6 \mathrm{~B}$ ), suggesting that posttranslational modifications such as glycosylation of mCAR-D1D2-w/oFc enhanced the dimeric state. We therefore analyzed the self-association of chCAR-D1D2-w/oFc after deglycosylation by PNGaseF compared with untreated chCAR-D1D2-w/oFc. Indeed, binding experiments revealed that high-affinity homodimeric complex formation is promoted by $N$-glycosylation (Fig. 6C). Gel filtration analysis also showed that mCAR-D1D2 is predominantly a monomer at low concentrations, whereas chCAR-D1D2-w/oFc predominantly associated as a dimer if the molecular masses of the peaks of about 25 versus $50 \mathrm{kDa}$, respectively, were compared (Fig. 6D).

In summary, these results indicate that CAR mediates homotypic cell aggregation via homophilic binding by its extracellular Ig domains.

\section{The crystal structure of mCAR-D1D2 reveals a U-shaped homodimer}

To obtain additional insight into the heterophilic and homophilic binding activities of CAR, the structure of the complete extracellular part of CAR (mCAR-D1D2) was determined by $\mathrm{x}$-ray crystallography at $2.19 \AA$ resolution (Fig. 7).

In the crystal, two D1 domains, related by a twofold crystallographic symmetry, interact reciprocally in head-to-head manner, placing their D2 domains on the same side and forming a U-shaped arrangement (Fig. 7E). The dimer interface has a size of $684 \AA^{2}$ per monomer and is located at a distal part of D1, opposite to the D1-D2 junction. This interface is formed by various side chains derived from $\beta$-strands $G, F, C, C^{\prime}$, and $C^{\prime \prime}$, as well as the
FG-connecting loop (Fig. 7F). Intermolecular polar interactions within the dimer interface involve four salt bridges, formed between D45 and K123 as well as E56 and K121, and two hydrogen bonds, formed between the hydroxyl group of Y83 and the backbone carbonyl group of P126 (Fig. 7G). Side chain-derived hydrophobic interactions involve Y83, which packs against P126 and A125, as well as V128 interacting with V70 and L73. After dimer formation, most of these groups are completely shielded from the solvent. We therefore conclude that the exclusion of water molecules from hydrophobic groups combined with reciprocal interaction of buried polar and charged groups favor the D1-based homodimerization of CAR. A similar interface was previously reported for the single D1 structure of human CAR (van Raaij et al., 2000). Consistently, the D1 domain structure of mCAR-D1D2 described here is similar to the single D1 domain from human CAR (accession number 1EAJ) (van Raaij et al., 2000) and adenovirus-fiber knob-complexed D1 domains (accession numbers 1KAC, 2J2J, and 2WBW) (Bewley et al., 1999; Seiradake et al., 2006), as indicated by root mean square deviation (RMSD) values of $<0.8 \AA$ after least-squares superpositions of 108 pairs of $\alpha$-carbon atoms, respectively. The only regions where structural deviations were observed involve loop-forming residues connecting strands $\mathrm{C}^{\prime \prime}$ and $\mathrm{D}$ in isolated $\mathrm{D} 1$, as well as strands $\mathrm{C} 1$ and $\mathrm{Cl}^{\prime}$ in the D1-fiber knob complex. Similar deviations are also observed between these two D1 reference structures, suggesting that these differences are probably caused by crystal packing.

D2 is composed of amino acids 139-230 of mCAR. In contrast to D1, D2 is arranged as a $\beta$-sandwich whose two $\beta$-sheets are formed by only three antiparallel $\beta$-strands (Fig. $7 A, B$ ). The sheets are derived from $\beta$-strands $\mathrm{A} / \mathrm{B} / \mathrm{E}$ and $\mathrm{C} / \mathrm{F} / \mathrm{G}$, respectively, and their overall fold is similar to that of $\mathrm{C}$-type Ig domains (Bork et al., 1994), with the exception that the D strand, typically extending strand $\mathrm{E}$, is replaced by a short helix. Two disulfide bonds link the sheets, connecting strand A to $\mathrm{G}$ and strand B to F. The C-terminal end of D2 is located at an extension of strand G and would proceed, via a five-residue linker, to an $\alpha$-helical transmembrane segment. A nuclear magnetic resonance (NMR) structure of CAR D2 (PDB accession number 2NPL; chain X) (Jiang and Caffrey, 2007) does not superimpose well with the D2 part of mCAR-D1D2, as indicated by an RMSD value of $4.3 \AA$ for all pairs of $\alpha$-carbons. Prominent deviations between the structures are observed for strands A, B, and E and helix D. As the NMR structure similarly deviates from other C-type Ig structures deposited in the PDB, whereas the D2 part of mCAR-D1D2 could be superimposed with these structures yielding RMSD values below $1.5 \AA$, we assume that the structural model presented here more closely represents the native fold of CAR's extracellular 

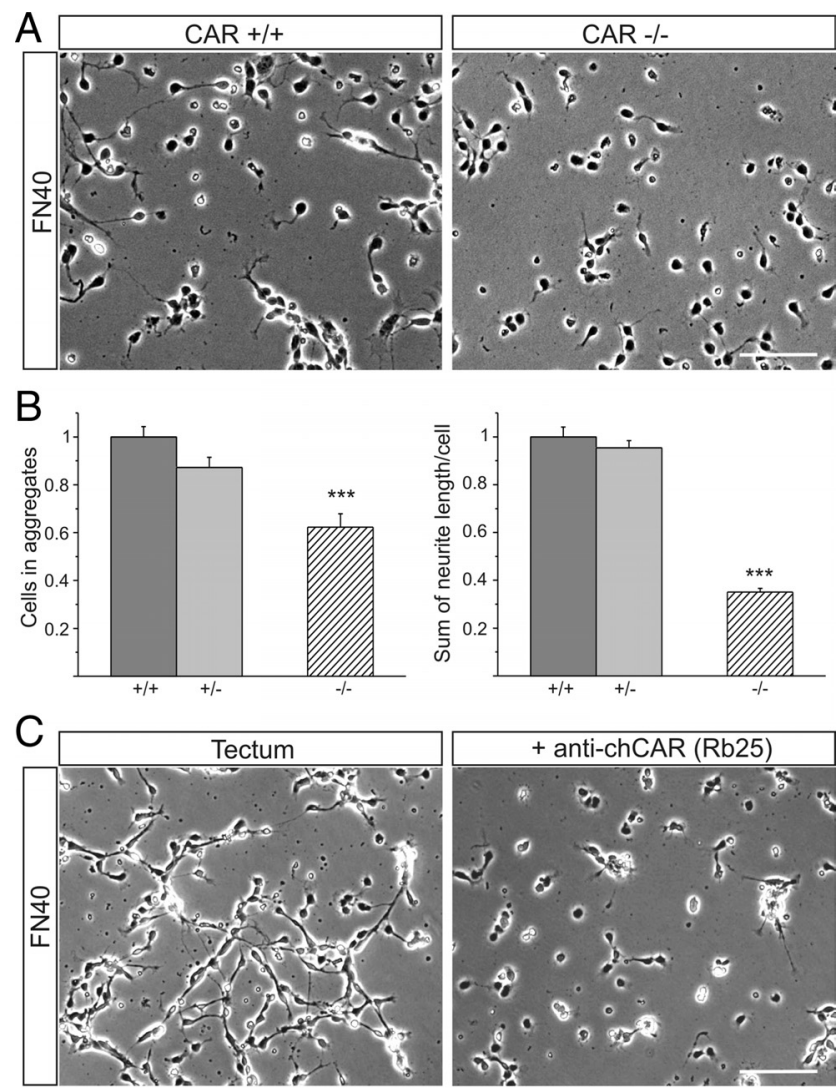

\section{D}
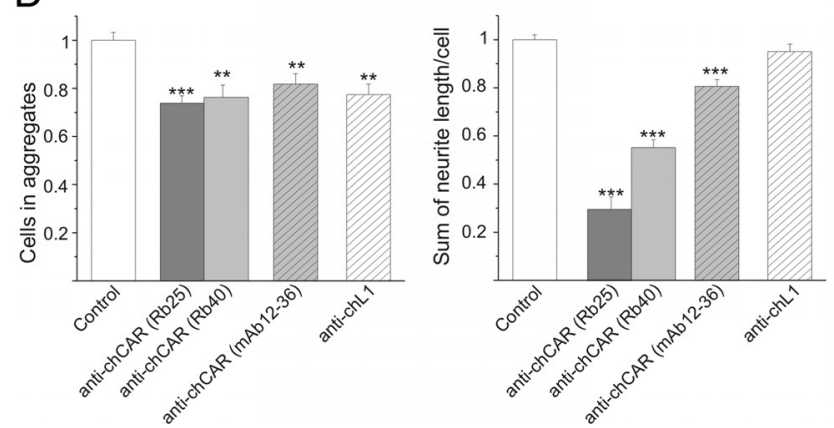

Figure 5. The CAR-FN40 interaction is important for neurite extension. $\boldsymbol{A}, \boldsymbol{B}, \mathrm{E} 11$ wild-type or CAR-deficient neural cells were plated on immobilized FN40. CAR-/- cells extend fewer neurites and form fewer aggregates compared with CAR $+/+$ cells. $C, D$, Aggregate formation and neurite extension of chick tectal cells (E6) on FN40 is blocked by antibodies to chCAR, whereas antibodies to chL1 do not interfere with neurite extension. Clusters of more than three cells were considered as aggregates. Cell numbers are expressed as mean per optical view field \pm SEM and were normalized to wild-type or untreated cells. Neurite length was determined per view field divided by number of attached cells. ${ }^{* *} p<0.005$; ${ }^{* * *} p<0.0005$. Scale bars, $100 \mu \mathrm{m}$.

domains, potentially because of the presence of $\mathrm{D} 1$, which may stabilize the fold of D2.

D1 and D2 of each CAR monomer associate in a head-to-tail manner, with their $\beta$-sandwiches at similar relative positions and forming an elongated rod-like structure, which is slightly wider in diameter on the D1 side (Fig. $7 A, B$ ). Looking onto their sandwiched $\beta$-sheets (Fig. $7 B$ ), the two domains are inclined, with respect to each other, at an angle of $\sim 8^{\circ}$ toward one side. At the side of inclination, the molecule has a dumbbell-shaped surface, whose protrusions are formed by the globular Ig domains, whereas the opposite side shows an almost flat surface. The junction between the two domains has the narrowest diameter of the
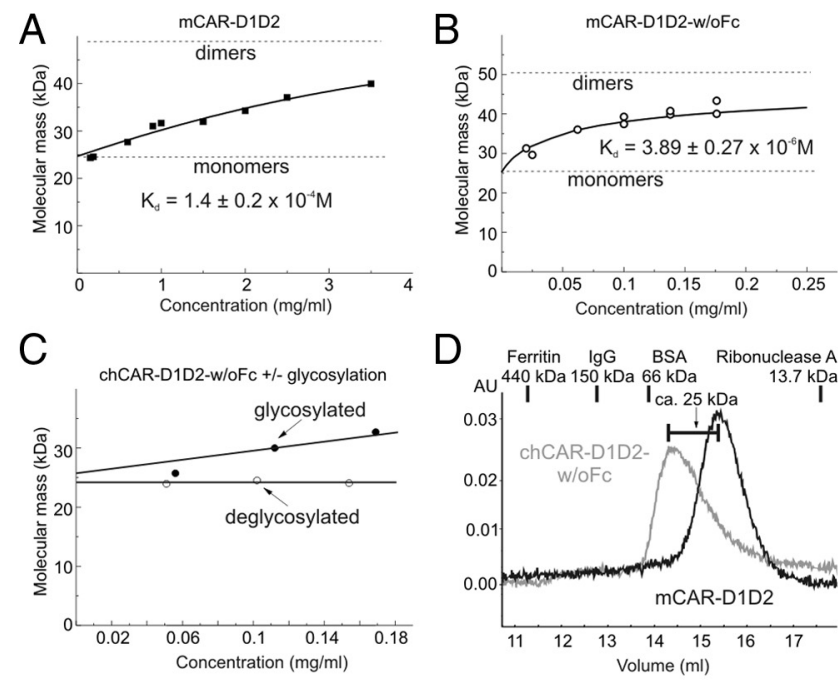

D Ferritin IgG BSA Ribonuclease $A$

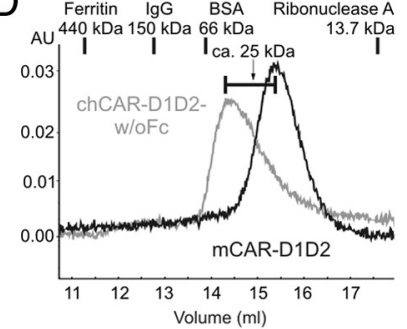

E

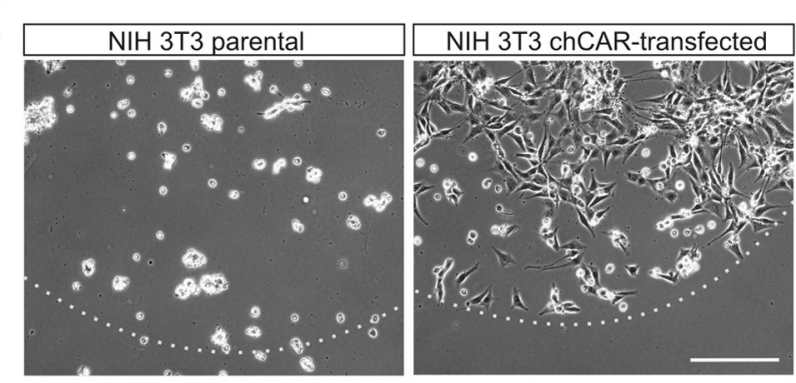

F mCAR-D1D2 immobilized

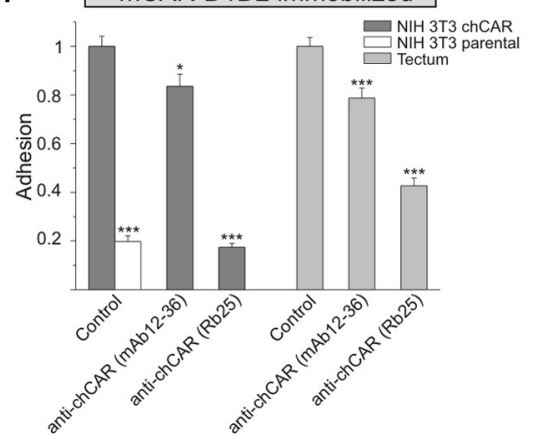

Figure 6. Homophilic binding of CAR-D1D2 domains is enhanced by N-glycosylation, and CAR-expressing cells bind to immobilized mCAR-D1D2.A, Equilibrium sedimentation analysis of mCAR-D1D2. At concentrations up to $3.5 \mathrm{mg} / \mathrm{ml}$, a monomer- dimer equilibrium is observed. $\boldsymbol{B}$, mCAR-D1D2-w/oFc forms a monomer-dimer equilibrium. Note that in contrast to mCARD1D2, 50\% of mCAR-D1D2-w/oFc are found in dimers at a concentration of $170 \mu \mathrm{g} / \mathrm{ml}$. C, At concentrations up to $170 \mu \mathrm{g} / \mathrm{ml}$, self-association of chCAR-D1D2-w/0Fc is enhanced by $\mathrm{N}$-glycosylation. chCAR-D1D2-w/oFc was deglycosylated by PNGaseF for $2 \mathrm{~h}$ at $37^{\circ} \mathrm{C}$. Selfassociation was monitored at three different concentrations by equilibrium sedimentation. Underglycosylated chCAR-D1D2-w/oFc served as the control. D, Comparison of size exclusion chromatography profiles (Superdex 200 HR) of mCAR-D1D2 (black) and chCAR-D1D2-w/oFc (gray). Identical concentrations were applied $(0.5 \mathrm{ml}$ of $130 \mu \mathrm{g} / \mathrm{ml}$ at a flow rate of $0.5 \mathrm{ml} / \mathrm{min}$ in PBS). m(AR-D1D2 runs predominantly as a monomer, and chCAR-D1D2-w/0Fc runs predominantly as a dimer. The positions of standard proteins are shown at the top. The calculated size difference between the peaks of mCAR-D1D2 and chCAR-D1D2-w/oFc is equivalent to the size of the mCAR-D1D2 monomer (25 kDa). The theoretical masses are 24378.5 and 24433.6 for chCAR-D1D2-w/0Fc and mCAR-D1D2, respectively, and the measured mass of glycosylated chCAR-D1D2-w/oFc is 26081.5 as determined by mass spectrometry. $\boldsymbol{E}, \boldsymbol{F}$, chCAR-transfected NIH $3 \mathrm{~T} 3$ cells attach to immobilized mCAR-D1D2 and spread while parental cells are unable to attach. Attachment is disturbed by species-specific antibodies to chCAR (Rb25 or mAb12-36). Culture dishes were precoated with $2 \mu$ l of mCAR-D1D2 (100 $\mu \mathrm{g} / \mathrm{ml})$ in their center. The border of the coated area is indicated by a broken line. Means \pm SEM are normalized. ${ }^{*} p<0.05$; ${ }^{* * *} p<0.0005$. Scale bar, $200 \mu \mathrm{m}$. 

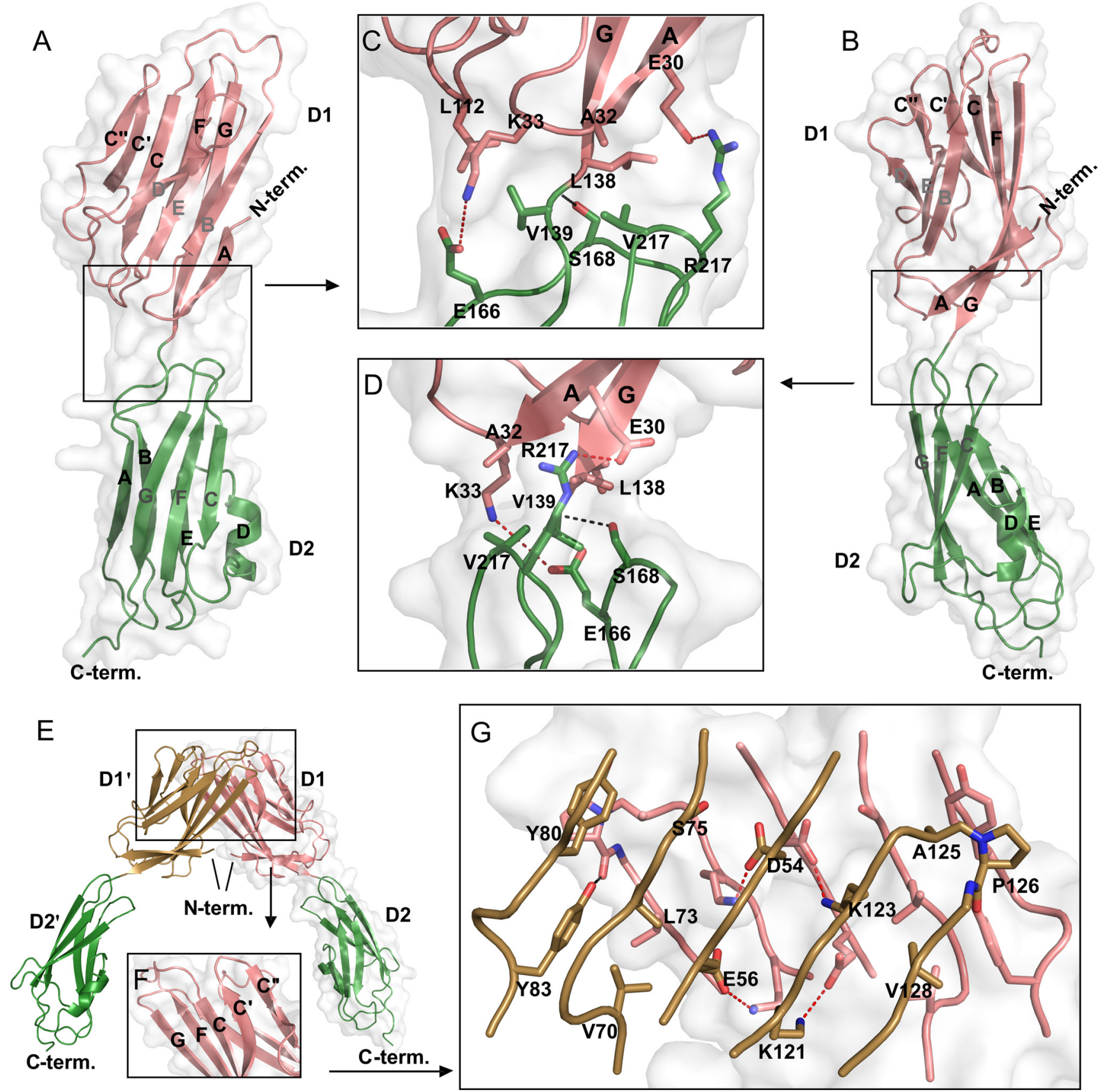

Figure 7. Crystal structure of extracellular mCAR-D1D2 reveals a U-shaped dimer. A-D, Secondary and tertiary structure of mCAR-D1D2; parts belonging to D1 and D2 are colored pink and green, respectively. The molecular contact area is displayed as a transparent gray surface. $A, B, 0$ verview of the lg folds in D1 and D2. $\beta$-Strands in D1 and D2 are labeled in uppercase letters. Labels of the two sheets forming a $\beta$-sandwich are colored black and gray, respectively. The view in $B$ is rotated by $90^{\circ}$ with respect to $A$. C, D, Layout of the D1-D2 junction. Side chains defining the junction are displayed as sticks, with noncarbon atoms colored according to (PK conventions. Hydrogen bonds and salt bridges/electrostatic contacts are shown as dashed black and red lines, respectively. The view in $\boldsymbol{D}$ is rotated by $90^{\circ}$ with respect to $A$. $E$, Overview of two symmetry-related $m C A R$ monomers (D1 and D2 vs D1 ${ }^{\prime}$ and $D 2^{\prime}$ ) forming a U-shaped dimer. The contact surface is shown only for one mCAR molecule (D1 and D2), and the D1' domain is colored brown. $F$, Structural elements forming the dimer interface shown for D1 in $\boldsymbol{E}$. G, Detailed view of interactions inside the dimer interface shown in $\boldsymbol{E}$. The layout according to $\boldsymbol{C}$ and $\boldsymbol{D}$ is shown. For a better overview, labels are shown for domain D1' only but can be inferred to D1 by symmetry. C-term., C terminus; $\mathrm{N}$-term., $\mathrm{N}$ terminus.

rod, defining the dumbbell's "grip." Residues forming the junction are derived from $\beta$-strands $\mathrm{A}$ and $\mathrm{G}$, the $\mathrm{AB}$ - and $\mathrm{CC}^{\prime}$ connecting loops on the $\mathrm{D} 1$ side, residues at the domain termini (L138 and V139), and the loops connecting BC and FG in D2. The junction is stabilized mainly by polar interactions: a hydrogen bond is formed between the S168 side chain and the backbone carbonyl oxygen of V139, a salt bridge is formed between R217 and $\mathrm{E} 30$, and another electrostatic contact is observed involving
K33 and E166 (Fig. 7C,D). Hydrophobic interactions are observed between side chains of A32, L138, V139, and V217. All these residues are organized in a parallel arrangement, thereby defining the junction's longest extension, which is oriented approximately parallel to the sheets forming D1 and D2 (Fig. 7C). In a perpendicular orientation (Fig. $7 D$ ), the junction is much smaller. The relatively abrupt transition between the two globular domains, which involves only two amino acids, appears to limit 

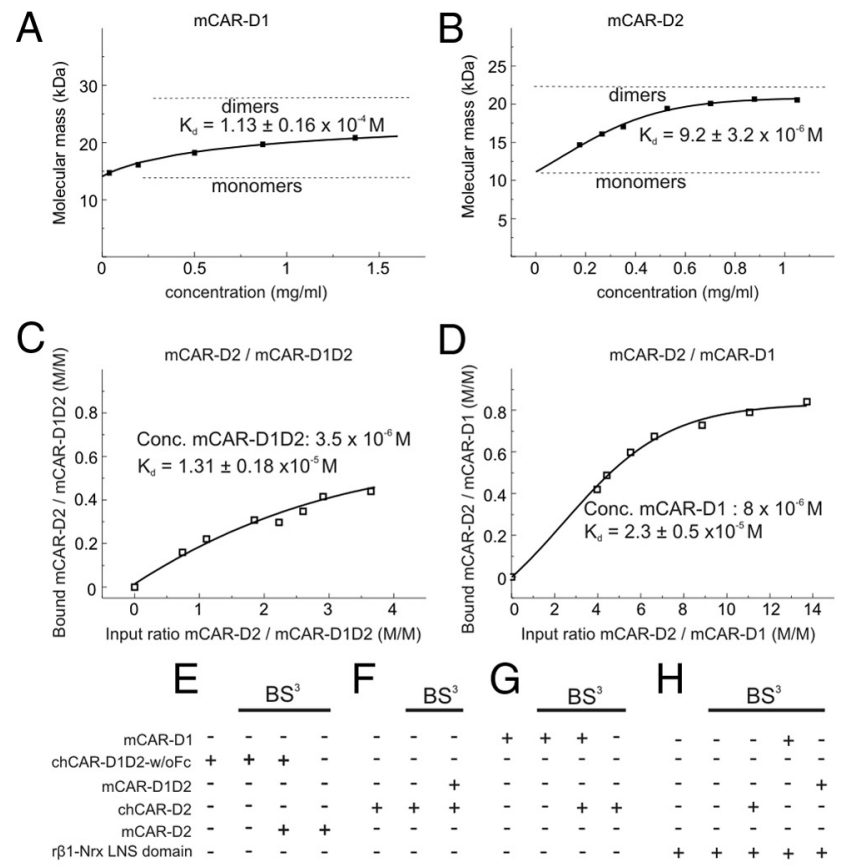

$\mathrm{G} \mathrm{BS}^{3}$

$\mathrm{H}$
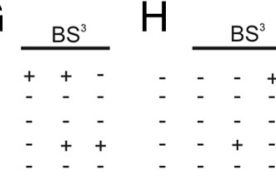

$\frac{\mathrm{BS}^{3}}{-+{ }^{2}+}$

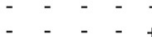

$-\quad+--$

$++++$

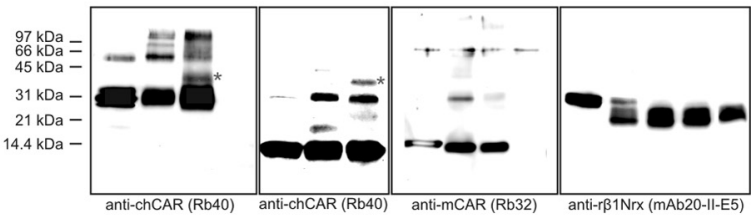

I

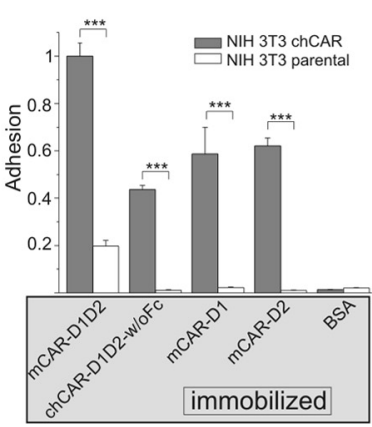

$J$

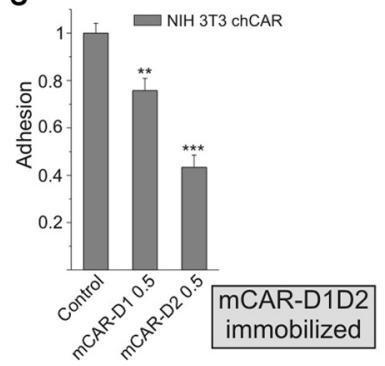

$\mathrm{K}$

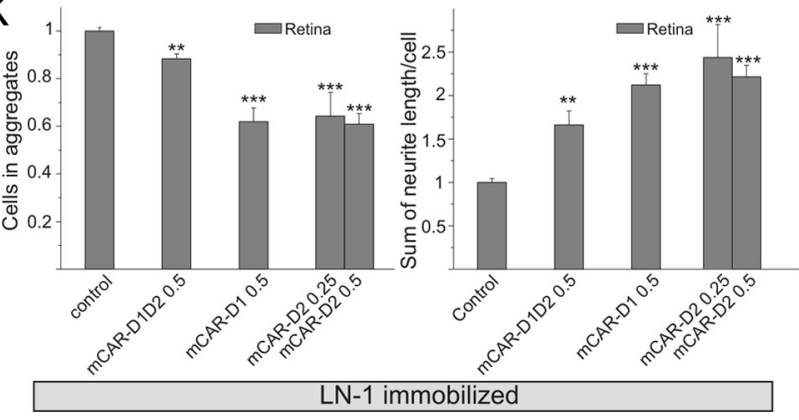

Figure 8. Homophilic adhesion is mediated by $D 1$ and D2. A-D, mCAR-D1 and mCAR-D2 are able to self-associate as revealed by analytical ultracentrifugation and represent a monomerdimer equilibrium in solution. mCAR-D1 or mCAR-D2 binds to mCAR-D1D2. $\boldsymbol{E}-\boldsymbol{H}$, Chemical cross-linking of CAR polypeptides. Western blots of extracellular CAR domains probed with antibodies against chCAR or mCAR are shown. $E$, chCAR-D1D2-w/oFc migrates as a band at 30 $\mathrm{kDa}$ and a weaker band at $60 \mathrm{kDa}$, which represents a dimer. Cross-linking with $\mathrm{BS}^{3}$ leads to an increase of dimers and to the occurrence of higher oligomers as well, and to a band at $40 \mathrm{kDa}$, which represents a heterodimer of chCAR-D1D2-w/oFc and mCAR-D2. $\boldsymbol{F}$, Similar results are revealed when mCAR-D1D2 and chCAR-D2 are cross-linked. (mCAR-D1D2 migrates as a band of $25 \mathrm{kDa}$ and a weak dimer band at $50 \mathrm{kDa}$.) G, chCAR-D2 and mCAR-D1 migrate as a monomer and dimer. (Note that the dimeric mCAR-D1 band at $30 \mathrm{kDa}$ becomes less intense because of the the flexibility of the junction, whereas its unidirectional organization suggests that the two domains may be only slightly relocated by hinge-like motions, librating along the junctions' minor extension. This kind of motion is in agreement with simulated vibrational modes obtained from normal mode analyses.

\section{Both Ig domains of CAR are implicated in homophilic binding}

To test the functional significance of the U-shaped homodimer of CAR, additional binding experiments and adhesion assays using polypeptides with single and two Ig domains of CAR were performed (Fig. 8). The affinities of the fiber knob Ad2 to mCAR-D1, chCAR-D1D2-Fc, or mCAR-D1D2 were comparable, suggesting that the GFCC' surfaces of the D1 domain in these three polypeptides were similarly preserved (Table 2 ). D1 reveals self-association and binding to mCAR-D1D2 $\left(K_{\mathrm{d}}=1.74 \pm 0.37 \times 10^{-5} \mathrm{M}\right)$ (Table $3)$. Interestingly, $D 2$ also self-associated and interacted with mCARD1D2 $\left(1.31 \pm 0.18 \times 10^{-5} \mathrm{M}\right)$, as well as with D1 $\left(2.3 \pm 0.5 \times 10^{-5} \mathrm{M}\right)$. Chemical cross-linking of extracellular CAR domains with $\mathrm{BS}^{3}$ was used to obtain additional evidence for these homophilic and heterophilic binding activities of D1 and D2. In these studies, recombinant domains from chick or mouse CAR were combined, which allowed the identification of cross-linked products with antibodies that identify only CAR domains from mouse or chick. After cross-linking, Western blot analysis identified monomeric, homodimeric, trimeric, and tetrameric complexes of chCAR-D1D2-w/oFc. An additional cross-linked species, with an apparent mass of $40 \mathrm{kDa}$, indicates that the D1 monomer also binds $\mathrm{D} 2$ (Fig. $8 \mathrm{E}$, asterisk). chD2 is found as a monomer and dimer and associates with mCAR-D1D2 (Fig. $8 F$ ). Similarly, $\mathrm{mD} 1$ is monomeric as well as dimeric and binds to chD2 (Fig. $8 G)$. No cross-linking products were observed between CAR domains and the $\beta 1$-LNS domain of neurexin (Fig. $8 H$ ).

Furthermore, in cell-attachment assays, chCAR-expressing $\mathrm{NIH} 3 \mathrm{~T} 3$ cells adhered to immobilized mCAR-D1 or mCAR-D2 and mCAR-D1 or mCAR-D2 in solution interfered with the adhesion to immobilized mCAR-D1D2 (Fig. 8I,J). Consistently, the number of retinal cells found in aggregates decreased, and the neurite length on an LN-1 substratum increased in the presence of mCAR-D1 or mCAR-D2 in solution, most likely by interfering with the homophilic binding of CAR required for the formation of aggregates (Fig. $8 \mathrm{~K}$ ).

In summary, binding was observed between D1-D1, between D2-D2, and between D1-D2, and the combined results of the adhesion assays implicate D1, as well as D2, in CAR-CAR homophilic interaction. The crystal structure detailed above therefore most likely characterizes only one of several possible homophilic configurations of CAR (see Discussion).

\section{Discussion}

An unusual feature that distinguishes CAR from many cell adhesion proteins of the Ig superfamily is its predominant expression on neural cells during embryonic development, followed by a strong downregulation at early postnatal stages (Xu and Crowell,

\section{$\leftarrow$}

binding chD2 that is not recognized by anti-mouse (AR.) $\boldsymbol{H}$, mCAR domains are not cross-linked to the $\beta 1$-LNS domain of rat neurexin. I, chCAR-expressing 3T3 cells adhered to immobilized mCAR-D1D2, chCAR-D1D2-w/oFc, mCAR-D1, or mCAR-D2.J, The attachment of CAR-expressing 3 T3 cells was blocked by mCAR-D1 or mCAR-D2 in solution at a concentration of $0.5 \mathrm{mg} / \mathrm{ml}$. $\boldsymbol{K}$, Formation of aggregates of tectal cells was blocked by mCAR-D1 or mCAR-D2 in solution while the formation of neurites was promoted. Concentrations (Conc.) are indicated in milligrams per milliliters. Error bars indicate SEM. ${ }^{* *} p<0.005 ;{ }^{* * *} p<0.0005$. 
Table 3. Dissociation constants of the homophilic interactions of CAR domains

\begin{tabular}{|c|c|c|c|c|}
\hline$K_{\mathrm{d}}(\mathrm{M})$ & mCAR-D1D2-w/oFc & mCAR-D1D2 & mCAR-D1 & mCAR-D2 \\
\hline mCAR-D1D2 & & $1.4 \pm 0.2 \times 10^{-4}$ & $1.74 \pm 0.37 \times 10^{-5}$ & $1.31 \pm 0.18 \times 10^{-5}$ \\
\hline mCAR-D1D2-w/oFc & $3.89 \pm 0.27 \times 10^{-6}$ & & & \\
\hline mCAR-D1 & & $1.74 \pm 0.37 \times 10^{-5}$ & $1.13 \pm 0.16 \times 10^{-4}$ & $2.3 \pm 0.5 \times 10^{-5}$ \\
\hline mCAR-D2 & & $1.31 \pm 0.18 \times 10^{-5}$ & $2.3 \pm 0.5 \times 10^{-5}$ & $9.2 \pm 3.2 \times 10^{-6}$ \\
\hline
\end{tabular}

1996; Honda et al., 2000). However, its function on neural cells is unknown. In this study, we performed a series of adhesion/neurite outgrowth assays using neural cells and binding studies and related these results to crystallographic data. The major findings of our study are as follows: (1) CAR is self-associating but also binds in a heterophilic manner to ECM glycoproteins such as FN, LN-1, TN-R, and agrin; (2) the D2 domain of CAR binds to the heparin-binding domain 2 of $\mathrm{FN}$; (3) this interaction mediates neurite extension in vitro; (4) both extracellular domains D1 and D2 contribute directly to homophilic binding; and (5) crystallographic studies predict a U-shaped homodimer of extracellular CAR domains that, for steric reasons, might exist within the plasma membrane of the same cell (cis-interaction).

The molecular contacts generating this U-shaped dimeric complex are similar to the U-structure observed for the CARrelated protein JAM-A from mouse and human (Kostrewa et al., 2001; Prota et al., 2003). In addition, two U-like mouse JAM-A homodimers in opposite orientations associate in trans- via another symmetric interface within their membrane distal domains. This additional site of interaction in JAM-A D1 that has not been observed for human JAM-A allows the generation of an open assembly, which can be extended by attaching additional U-shaped JAM-A dimers. Based on these structural observations on JAM-A, a model of trans-homophilic membrane interaction has been proposed (Kostrewa et al., 2001). However, this additional interface is not conserved between JAM-A and CAR and involves mainly backbone groups. In our mCAR-D1D2 crystal, we did not observe a corresponding arrangement that would allow the interaction of U-like homodimers in opposite orientations.

The combined data of our binding and adhesion experiments led us to conclude that additional arrangements of CAR monomers other than that one observed in the crystal have to be assumed. These conformations might not be easily reproduced under crystallization conditions. For instance, our adhesion assays reveal that CAR-expressing cells bind specifically to immobilized CAR-D2 and soluble CAR-D2 interferes with the attachment of CAR-expressing cells to CAR-D1D2. Furthermore, binding analyses showed that CAR-D2 self-associates and forms heterodimers with CAR-D1. We therefore expect a flexible ectodomain of CAR allowing conformational shifts for cis- or trans-interactions (Fig. 9A). Thus, trans-homophilic adhesion could be initiated by CAR monomers from different cells via the observed D1-D1 interface (Fig. 7E). This mode of homophilic D1-D1 association would require a slight reorientation of the D1 domain, which could be allowed by the flexible 5 aa linker at the $\mathrm{C}$ terminus of D2 and/or by a structural reorganization of the Ig domains at their junction. Such a kinked arrangement of D1 and D2, which deviates from the colinear arrangement in our crystal structure by $\sim 50^{\circ}$, has been observed in a low-resolution electron microscopy structure of human CAR (He et al., 2001). Both parts, the linker and junction, have been implicated to provide some degree of flexibility to the protein because of their relatively low electron densities. We hypothesize that CAR-mediated adhesion could be further strengthened by an additional change in the conformation, which relocates the Ig domains in a manner in
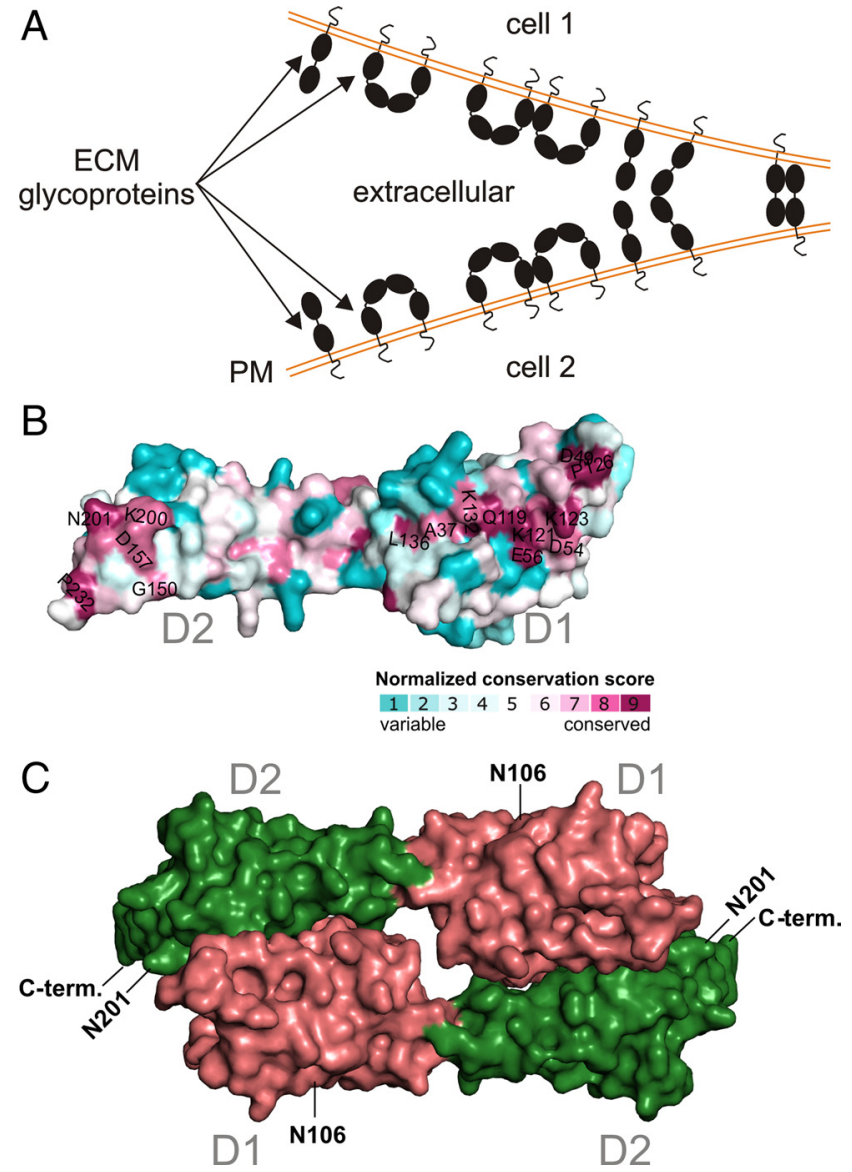

Figure 9. Summary of molecular interactions of CAR. $A$, Scheme of putative molecular interactions of CAR on the neural plasma membrane (PM). Possible homophilic interactions of CAR are as follows: the D1-D1 self-association revealed by the U-shaped crystal structure most likely occurs between CAR polypeptides attached to the same plasma membrane. Additional binding and adhesion data suggest that homophilic interactions of CAR between two cells result from an antiparallel D1-D2 interaction. Heterophilic interactions to ECM glycoproteins are indicated by arrows. $B, C$, Proposed model for two mCAR-D1D2 monomers associated via two D1-D2 interfaces based on molecular docking simulations. Molecular contact surfaces corresponding to D1 and D2 are colored pink and green, respectively. Glycosylation sites (N106 and N201) and C termini are labeled. Normalized conservation score indicated by a color code. . C-term., C terminus; $\mathrm{N}$-term., $\mathrm{N}$ terminus.

which they interact reciprocally, forming two D1-D2 interfaces in a linear arrangement from opposing cells. After such a binding, the linker would be placed on opposite ends and the glycosylated side chains would remain on the surface of the dimer. This kind of interaction has not yet been observed in a crystal, but molecular docking indicates that such an arrangement may be possible (Fig. 9B,C). In particular, a complementary interface between the $\mathrm{D} 1$ region involved in the $\mathrm{D} 1$ homodimerization interface and another strongly conserved surface area of D2 was detected, which could potentially engage in this kind of interaction. Furthermore, on the surface of the same cell, such a kind of arrangement appears to be disfavored and therefore unlikely because of 
the overall negative surface potential of CAR's extracellular domains at a neutral $\mathrm{pH}\left(p I_{\text {calc }}=5.2\right)$. To allow this type of association between CAR molecules on the surface of the same cell, CAR polypeptides need to assemble at a close distance to membranes' phospholipid groups. Hence, CAR dimerization in a linear arrangement with two D1-D2 interfaces may occur only between neighboring cells. To confirm this trans-association mode, which is predicted from the adhesion and binding studies, additional structural studies will be required. Interestingly, a conformational change between cis- and trans-homodimerization has also been discussed for CEACAM1, which is composed of four Ig domains (Klaile et al., 2009).

Our data indicate that CAR is able to interact with several partners. Taking into account previously published adhesion and binding studies on CAR (Freimuth et al., 2008), the direct binding of CAR to ECM glycoproteins was unexpected. The FN binding site was mapped to the D2 domain of CAR and was located in a particular FN fragment, FN40. The affinity between the different recombinant polypeptides and ECM glycoproteins was higher than the affinity of the homophilic CAR interactions. Most importantly, adhesion and neurite outgrowth assays provide independent support for an interaction between CAR and FN or LN-1. Thus, soluble CAR domains or antibodies to CAR, monoclonal or polyclonal, strongly blocked attachment and neurite extension of neural cells on ECM glycoproteins FN or LN-1. Moreover, compared with wild-type neurons, CAR-deficient neurons only poorly adhered and formed few short neurites on an FN40 substrate. However, we detected no change in neurite extension at early embryonic stages in CAR mutant mice that die at E11 because of malformations of the heart. CAR also binds to agrin and TN-R, and the affinities of these interactions are similar to the one observed for FN. In light of the expression of CAR at the neuromuscular junction (Shaw et al., 2004) and the coexpression of agrin and CAR in the inner plexiform layer of the developing retina (Kröger et al., 1996), the interaction between agrin and CAR deserves more attention.

Evidence is accumulating that the extracellular domains of CAR and those of other members of this class of Ig-like proteins are engaged in several heterophilic interactions. For example, binding of CAR-D1 to D2 of JAM-L appears to be required for transmigration of neutrophils across tight junctions (Zen et al., 2005), and JAM-L constitutively associates on monocytes and T-lymphocytes with the VLA-4 ( $\alpha 4 \beta 1)$ integrin (Luissint et al., 2008). The second Ig domain of JAM-A interacts with LFA-1, whereas JAM-C binds to $\alpha \mathrm{M} \beta 2$ (MAC-1) integrin (Ostermann et al., 2002; Chavakis et al., 2004). Nevertheless, the high concentration of CAR at cell-cell contact sites of cultivated cells, at intercalated discs on cardiomyocytes, and at tight junctions of epithelial cells in vivo might indicate that CAR mainly acts as a homophilic adhesion protein at these sites to form cell-cell contacts. The clustered distribution of CAR in neurons might also reflect mechanisms of self-association of native CAR that were not yet studied.

The trimeric fiber knob binds up to three D1 domains of CAR, most likely attached to the same membrane (Freimuth et al., 2008). Therefore, fiber knob possibly suppresses CAR-CAR binding between opposing cells (Walters et al., 2002) but might mimic homophilic CAR interaction. Several mechanisms might explain the stimulation of neurite extension by fiber knob and by extracellular CAR domains. For instance, these reagents might disrupt neural cell-cell contacts, which then allows an increased interactions of neural cells with ECM glycoproteins via integrins or via the D2 domain of CAR. Alternatively or in addition, intra- cellular signaling cascades might be activated by the fiber knob via CAR, resulting in a promotion of neurite extension. Provided that CAR can be reexpressed on adult axons, future research will reveal whether the neurite outgrowth promoting activity of fiber knob observed in this study might be also helpful for axon regeneration after injury.

\section{References}

Altschul SF, Gish W, Miller W, Myers EW, Lipman DJ (1990) Basic local alignment search tool. J Mol Biol 215:403-410.

Asher DR, Cerny AM, Weiler SR, Horner JW, Keeler ML, Neptune MA, Jones SN, Bronson RT, DePinho RA, Finberg RW (2005) Coxsackievirus and adenovirus receptor is essential for cardiomyocyte development. Genesis 42:77-85

Awasthi V, Meinken G, Springer K, Srivastava SC, Freimuth P (2004) Biodistribution of radioiodinated adenovirus fiber protein knob domain after intravenous injection in mice. J Virol 78:6431-6438.

Bailey S (1994) The Ccp4 Suite-Programs for Protein Crystallography. Acta Crystallogr D Biol Crystallogr 50:760-763.

Behlke J, Ristau O, Schonfeld HJ (1997) Nucleotide-dependent complex formation between the Escherichia coli chaperonins GroEL and GroES studied under equilibrium conditions. Biochemistry 36:5149-5156.

Bergelson JM, Cunningham JA, Droguett G, Kurt-Jones EA, Krithivas A, Hong JS, Horwitz MS, Crowell RL, Finberg RW (1997) Isolation of a common receptor for coxsackie B viruses and adenoviruses 2 and 5 . Science 275:1320-1323.

Bewley MC, Springer K, Zhang YB, Freimuth P, Flanagan JM (1999) Structural analysis of the mechanism of adenovirus binding to its human cellular receptor, CAR. Science 286:1579-1583.

Bork P, Holm L, Sander C (1994) The immunoglobulin fold. Structural classification, sequence patterns and common core. J Mol Biol 242:309-320.

Chavakis T, Keiper T, Matz-Westphal R, Hersemeyer K, Sachs UJ, Nawroth PP, Preissner KT, Santoso S (2004) The junctional adhesion molecule-C promotes neutrophil transendothelial migration in vitro and in vivo. J Biol Chem 279:55602-55608.

Chen JW, Zhou B, Yu QC, Shin SJ, Jiao K, Schneider MD, Baldwin HS, Bergelson JM (2006) Cardiomyocyte-specific deletion of the coxsackievirus and adenovirus receptor results in hyperplasia of the embryonic left ventricle and abnormalities of sinuatrial valves. Circ Res 98:923-930.

Cohen CJ, Gaetz J, Ohman T, Bergelson JM (2001a) Multiple regions within the coxsackievirus and adenovirus receptor cytoplasmic domain are required for basolateral sorting. J Biol Chem 276:25392-25398.

Cohen CJ, Shieh JT, Pickles RJ, Okegawa T, Hsieh JT, Bergelson JM (2001b) The coxsackievirus and adenovirus receptor is a transmembrane component of the tight junction. Proc Natl Acad Sci U S A 98:15191-15196.

Comoletti D, Flynn R, Jennings LL, Chubykin A, Matsumura T, Hasegawa H, Südhof TC, Taylor P (2003) Characterization of the interaction of a recombinant soluble neuroligin-1 with neurexin-1beta. J Biol Chem 278:50497-50505.

Coyne CB, Voelker T, Pichla SL, Bergelson JM (2004) The coxsackievirus and adenovirus receptor interacts with the multi-PDZ domain protein-1 (MUPP-1) within the tight junction. J Biol Chem 279:48079-48084.

Denzer AJ, Gesemann M, Schumacher B, Ruegg MA (1995) An aminoterminal extension is required for the secretion of chick agrin and its binding to extracellular matrix. J Cell Biol 131:1547-1560.

Dorner AA, Wegmann F, Butz S, Wolburg-Buchholz K, Wolburg H, Mack A, Nasdala I, August B, Westermann J, Rathjen FG, Vestweber D (2005) Coxsackievirus-adenovirus receptor (CAR) is essential for early embryonic cardiac development. J Cell Sci 118:3509-3521.

Emsley P, Cowtan K (2004) Coot: model-building tools for molecular graphics. Acta Crystallogr D Biol Crystallogr 60:2126-2132.

Excoffon KJ, Hruska-Hageman A, Klotz M, Traver GL, Zabner J (2004) A role for the PDZ-binding domain of the coxsackie $\mathrm{B}$ virus and adenovirus receptor (CAR) in cell adhesion and growth. J Cell Sci 117:4401-4409.

Freimuth P, Springer K, Berard C, Hainfeld J, Bewley M, Flanagan J (1999) Coxsackievirus and adenovirus receptor amino-terminal immunoglobulin V-related domain binds adenovirus type 2 and fiber knob from adenovirus type 12. J Virol 73:1392-1398.

Freimuth P, Philipson L, Carson SD (2008) The coxsackievirus and adenovirus receptor. Curr Top Microbiol Immunol 323:67-87. 
Halfter W, Deiss S (1986) Axonal pathfinding in organ-cultured embryonic avian retinae. Dev Biol 114:296-310.

Halfter W, Reckhaus W, Kröger S (1987) Nondirected axonal growth on basal lamina from avian embryonic neural retina. J Neurosci 7:3712-3722.

Heinemann U, Bussow K, Mueller U, Umbach P (2003) Facilities and methods for the high-throughput crystal structural analysis of human proteins. Acc Chem Res 36:157-163.

He Y, Chipman PR, Howitt J, Bator CM, Whitt MA, Baker TS, Kuhn RJ, Anderson CW, Freimuth P, Rossmann MG (2001) Interaction of coxsackievirus B3 with the full length coxsackievirus-adenovirus receptor. Nat Struct Biol 8:874-878.

Holm L, Sander C (1995) Dali: a network tool for protein structure comparison. Trends Biochem Sci 20:478-480.

Honda T, Saitoh H, Masuko M, Katagiri-Abe T, Tominaga K, Kozakai I, Kobayashi K, Kumanishi T, Watanabe YG, Odani S, Kuwano R (2000) The coxsackievirus-adenovirus receptor protein as a cell adhesion molecule in the developing mouse brain. Brain Res Mol Brain Res 77:19-28.

Jiang S, Caffrey M (2007) Solution structure of the coxsackievirus and adenovirus receptor domain 2. Protein Sci 16:539-542.

Kirby I, Davison E, Beavil AJ, Soh CP, Wickham TJ, Roelvink PW, Kovesdi I, Sutton BJ, Santis G (2000) Identification of contact residues and definition of the CAR-binding site of adenovirus type 5 fiber protein. J Virol 74:2804-2813.

Klaile E, Vorontsova O, Sigmundsson K, Muller MM, Singer BB, Ofverstedt LG, Svensson S, Skoglund U, Obrink B (2009) The CEACAM1 N-terminal Ig domain mediates cis- and trans-binding and is essential for allosteric rearrangements of CEACAM1 microclusters. J Cell Biol 187:553-567.

Kostrewa D, Brockhaus M, D'Arcy A, Dale GE, Nelboeck P, Schmid G, Mueller F, Bazzoni G, Dejana E, Bartfai T, Winkler FK, Hennig M (2001) X-ray structure of junctional adhesion molecule: structural basis for homophilic adhesion via a novel dimerization motif. EMBO J 20:4391-4398.

Krissinel E, Henrick K (2007) Inference of macromolecular assemblies from crystalline state. J Mol Biol 372:774-797.

Kröger S, Horton SE, Honig LS (1996) The developing avian retina expresses agrin isoforms during synaptogenesis. J Neurobiol 29:165-182.

Lim BK, Xiong D, Dorner A, Youn TJ, Yung A, Liu TI, Gu Y, Dalton ND, Wright AT, Evans SM, Chen J, Peterson KL, McCulloch AD, Yajima T, Knowlton KU (2008) Coxsackievirus and adenovirus receptor (CAR) mediates atrioventricular-node function and connexin 45 localization in the murine heart. J Clin Invest 118:2758-2770.

Lisewski U, Shi Y, Wrackmeyer U, Fischer R, Chen C, Schirdewan A, Juttner R, Rathjen F, Poller W, Radke MH, Gotthardt M (2008) The tight junction protein CAR regulates cardiac conduction and cell-cell communication. J Exp Med 205:2369-2379.

Lovell SC, Davis IW, Arendall WB III, de Bakker PI, Word JM, Prisant MG, Richardson JS, Richardson DC (2003) Structure validation by Calpha geometry: phi,psi and Cbeta deviation. Proteins 50:437-450.

Luissint AC, Lutz PG, Calderwood DA, Couraud PO, Bourdoulous S (2008) JAM-L-mediated leukocyte adhesion to endothelial cells is regulated in cis by alpha4beta1 integrin activation. J Cell Biol 183:1159-1173.

Mann S, Kröger S (1996) Agrin is synthesized by retinal cells and colocalizes with gephyrin [corrected]. Mol Cell Neurosci 8:1-13.

McCoy AJ, Grosse-Kunstleve RW, Adams PD, Winn MD, Storoni LC, Read RJ (2007) Phaser crystallographic software. J Appl Crystallogr 40:658-674.

Murshudov GN, Vagin AA, Dodson EJ (1997) Refinement of macromolecular structures by the maximum-likelihood method. Acta Crystallogr D Biol Crystallogr 53:240-255.

Nörenberg U, Wille H, Wolff JM, Frank R, Rathjen FG (1992) The chicken neural extracellular matrix molecule restrictin: similarity with EGF-, fibronectin type III-, and fibrinogen-like motifs. Neuron 8:849-863.

Ostermann G, Weber KS, Zernecke A, Schroder A, Weber C (2002) JAM-1 is a ligand of the beta(2) integrin LFA-1 involved in transendothelial migration of leukocytes. Nat Immunol 3:151-158.

Otwinowski Z, Minor W (1997) Processing of X-ray diffraction data collected in oscillation mode. Methods Emzymol 276:307-326.

Penn C, Klotz SA (1994) Binding of plasma fibronectin to Candida albicans occurs through the cell binding domain. Microb Pathog 17:387-393.
Perkins DN, Pappin DJ, Creasy DM, Cottrell JS (1999) Probability-based protein identification by searching sequence databases using mass spectrometry data. Electrophoresis 20:3551-3567.

Pierschbacher MD, Hayman EG, Ruoslahti E (1981) Location of the cellattachment site in fibronectin with monoclonal antibodies and proteolytic fragments of the molecule. Cell 26:259-267.

Pollerberg GE, Beck-Sickinger A (1993) A functional role for the middle extracellular region of the neural cell adhesion molecule (NCAM) in axonal fasciculation and orientation. Dev Biol 156:324-340.

Porter RR (1959) The hydrolysis of rabbit y-globulin and antibodies with crystalline papain. Biochem J 73:119-126.

Prota AE, Campbell JA, Schelling P, Forrest JC, Watson MJ, Peters TR, Aurrand-Lions M, Imhof BA, Dermody TS, Stehle T (2003) Crystal structure of human junctional adhesion molecule 1: implications for reovirus binding. Proc Natl Acad Sci U S A 100:5366-5371.

Rathjen FG, Schachner M (1984) Immunocytological and biochemical characterization of a new neuronal cell surface component (L1 antigen) which is involved in cell adhesion. EMBO J 3:1-10.

Rathjen FG, Wolff JM, Frank R, Bonhoeffer F, Rutishauser U (1987) Membrane glycoproteins involved in neurite fasciculation. J Cell Biol 104:343-353.

Roelvink PW, Mi LG, Einfeld DA, Kovesdi I, Wickham TJ (1999) Identification of a conserved receptor-binding site on the fiber proteins of CARrecognizing adenoviridae. Science 286:1568-1571.

Ruoslahti E, Hayman EG, Engvall E, Cothran WC, Butler WT (1981) Alignment of biologically active domains in the fibronectin molecule. J Biol Chem 256:7277-7281.

Schagger H, von Jagow G (1991) Blue native electrophoresis for isolation of membrane protein complexes in enzymatically active form. Anal Biochem 199:223-231.

Schumacher S, Volkmer H, Buck F, Otto A, Tarnok A, Roth S, Rathjen FG (1997) Chicken acidic leucine-rich EGF-like domain containing brain protein (CALEB), a neural member of the EGF family of differentiation factors, is implicated in neurite formation. J Cell Biol 136:895-906.

Seiradake E, Lortat-Jacob H, Billet O, Kremer EJ, Cusack S (2006) Structural and mutational analysis of human Ad37 and canine adenovirus 2 fiber heads in complex with the D1 domain of coxsackie and adenovirus receptor. J Biol Chem 281:33704-33716.

Shaw CA, Holland PC, Sinnreich M, Allen C, Sollerbrant K, Karpati G, Nalbantoglu J (2004) Isoform-specific expression of the Coxsackie and adenovirus receptor (CAR) in neuromuscular junction and cardiac intercalated discs. BMC Cell Biol 5:42.

Steen H, Mann M (2004) The ABC's (and XYZ's) of peptide sequencing. Nat Rev Mol Cell Biol 5:699-711.

Tomko RP, Xu R, Philipson L (1997) HCAR and MCAR: the human and mouse cellular receptors for subgroup $\mathrm{C}$ adenoviruses and group $\mathrm{B}$ coxsackieviruses. Proc Natl Acad Sci U S A 94:3352-3356.

Tovchigrechko A, Vakser IA (2006) GRAMM-X public web server for protein-protein docking. Nucleic Acids Res 34:W310-W314.

van Raaij MJ, Chouin E, van der ZH, Bergelson JM, Cusack S (2000) Dimeric structure of the coxsackievirus and adenovirus receptor D1 domain at 1.7 A resolution. Structure Fold Des 8:1147-1155.

Vriend G (1990) WHAT IF: a molecular modeling and drug design program. J Mol Graph 8:52- 6:29.

Walters RW, Freimuth P, Moninger TO, Ganske I, Zabner J, Welsh MJ (2002) Adenovirus fiber disrupts CAR-mediated intercellular adhesion allowing virus escape. Cell 110:789-799.

Weber C, Fraemohs L, Dejana E (2007) The role of junctional adhesion molecules in vascular inflammation. Nat Rev Immunol 7:467-477.

Xu R, Crowell RL (1996) Expression and distribution of the receptors for coxsackievirus B3 during fetal development of the Balb/c mouse and of their brain cells in culture. Virus Res 46:157-170.

Zen K, Liu Y, McCall IC, Wu T, Lee W, Babbin BA, Nusrat A, Parkos CA (2005) Neutrophil migration across tight junctions is mediated by adhesive interactions between epithelial coxsackie and adenovirus receptor and a junctional adhesion molecule-like protein on neutrophils. Mol Biol Cell 16:2694-2703. 